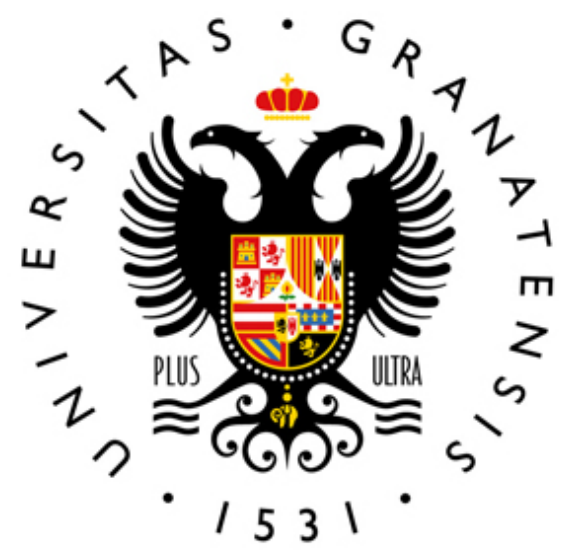

Estudio de galaxias en vacíos mediante análisis de datos IFU

Francisco Javier Flores Martín 



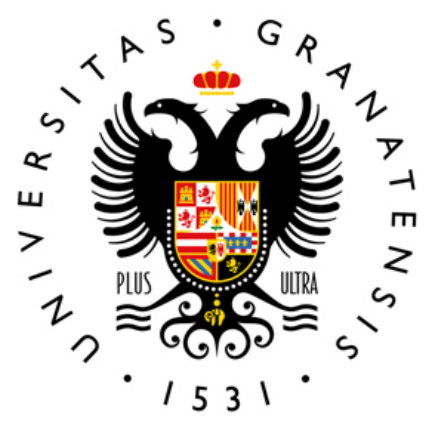

\title{
Estudio de galaxias en vacíos mediante análisis de datos IFU
}

Francisco Javier Flores Martín

\author{
Memoria del Trabajo Fin de Máster \\ Máster en Física y Matemáticas (FisyMat) \\ Universidad de Granada
}

Tutorizado por:

Prof./Dr. María Isabel Pérez Martín

Prof./Dr. Simon Verley

Mentorizado por:

D. Jesús Domínguez Gómez 


\section{Índice general}

1. Introducción 9

1.1. Mapping Nearby Galaxies at APO (MaNGA) . . . . . . . . . . . . 12

1.2. Nuestro objetivo . . . . . . . . . . . . . . . . . . . 13

1.3. Calar Alto Void Integral-field Treasury surveY (CAVITY) . . . . . . 15

1.3.1. Catálogo de Pan et al. [2012] . . . . . . . . . . . . . . 16

1.3.2. PMAS fiber PAck $(\mathrm{PPak}) \ldots \ldots \ldots \ldots$

1.4. Simulador de datos IFU . . . . . . . . . . . . . . . . . . . . 19

2. Caracterización de la señal/ruido (SN) en los cubos de PMAS/PPak 21

2.1. Preparación de los cubos . . . . . . . . . . . . . . . 21

2.1.1. Introducción . . . . . . . . . . . . . . 21

2.1.2. Obtención de mapas de SN . . . . . . . . . . . . . . . . 22

2.1.3. Obtención de las coordenadas de todos los píxeles de los mapas de señal ruido . . . . . . . . . . . . . 23

2.2. Simulación de datos PMAS/PPak con imágenes de SDSS. . . . . . . 25

2.2.1. Descarga de imágenes de SDSS. . . . . . . . . . . . . 25

2.2.2. Proceso de fotometría en imágenes SDSS utilizando el tamaño del spaxel del cubo . . . . . . . . . . . . . . . 25 
2.2.3. Comprobación de la imagen SDSS con aperturas de cubos de PMAS/PPak . . . . . . . . . . . . . 26

2.2.4. Resultados obtenidos con la fotometría de imágenes SDSS . . 29

3. Comparación de la SN de los cubos con las simulaciones 37

3.1. Introducción . . . . . . . . . . . . . . . 38

3.2. Bineado de Voronoi en las imágenes SDSS . . . . . . . . . . . . 38

3.3. Bineado de Voronoi en los cubos de PMAS/PPak . . . . . . . . . . . . 39

3.4. Comparación entre el bineado de Voronoi en los cubos de PMAS/PPak y en las imágenes de SDSS . . . . . . . . . . . . . . . . . . 41

3.5. Predicción del número de bines en otras galaxias no observadas con PMAS/PPak ....................... 42

3.6. Análisis del número de bines en función del redshift, color, R50, R90 y distancia al centro del vacío . . . . . . . . . . . . . . 42

3.6.1. Número de bines para cubos de 3 horas en función de 1.5 horas. 44

3.6.2. Número de bines frente al redshift. . . . . . . . . . . . . . . 44

3.6.3. Número de bines frente a la magnitud del spaxel central. . . . 44

3.6.4. Número de bines frente R50 y R $90 \ldots \ldots$. . . . . . . . . . 47

3.6.5. Número de bines frente a la fracción del radio efectivo. . . . . 47

3.6.6. Diagrama de color-magnitud de la galaxia. . . . . . . . . . . 48

4. Resumen y conclusión $\quad 51$

4.1. Calculador del tiempo de exposición . . . . . . . . . . . . . 51

4.2. Bineado de Voronoi . . . . . . . . . . . . . . . . . . 52

A. Simulador de número de bines en las imágenes SDSS 59 


\section{Resumen}

Calar Alto Void Integral-field Treasury surveY (CAVITY) es un proyecto puesto en marcha por la Universidad de Granada (UGR) y otras instituciones cuyo objetivo es el estudio de las galaxias en vacíos. El principal instrumento utilizado para los objetivos de CAVITY es el telescopio de 3.5m y el instrumento PMAS fiber PAck (PMAS/PPak) de Calar Alto situado en Almería (España).

A través de los datos IFU obtenidos ya calibrados, siguiendo la técnica descrita por García-Benito et al. [2015] de las galaxias en vacíos seleccionadas por el equipo de selección de CAVITY, hemos realizado un estudio espectral, quedándonos con una parte del espectro centrado en $5600 \AA$, de tal forma que hemos creado mapas de señal, ruido y señal/ruido a través del flujo del espectro en la región seleccionada. Estos mapas los hemos comparado con datos fotométricos en la banda g del proyecto Sloan Digital Sky Survey (SDSS, York et al. [2000]), la cual, es la banda más cercana al espectro elegido en los datos IFU. Con ello conseguimos realizar una comparación de señal, ruido y señal/ruido frente al brillo superficial de los datos SDSS y realizar un calculador de tiempo de exposición para el telescopio de $3.5 \mathrm{~m}$ y el instrumento PMAS/PPak de Calar Alto.

A continuación hemos realizado una técnica llamada bineado de Voronoi desarrollada por Cappellari et al. [2003] que nos permite agrupar datos obtenidos mediante el análisis espectral y compararlos con imágenes SDSS a través de un simulador desarrollado por Jesús Domínguez en su trabajo de Fin de Máster de FISYMAT (2017, título: Preparing For The First Light Of WEAVE-Apertif). Con esto conseguimos realizar un estudio comparativo de los datos obtenidos por PMAS/PPak y los datos obtenidos a través del simulador.

Para finalizar hemos realizado una simulación con 4866 galaxias en vacíos, el total de la muestra de CAVITY, para estudiar las galaxias más óptimas que podemos observar con el telescopio de 3.5m y el instrumento PMAS/PPak de Calar Alto, llegando a la conclusión que tenemos 1761 galaxias para la obtención de datos con 1.5 horas de exposición y 2577 galaxias para 3 horas de exposición.

Palabras Clave: catálogo, IFU, CAVITY, PMAS/PPak, Voronoi 


\begin{abstract}
Calar Alto Void Integral-field Treasury surveY (CAVITY) is a project of the University of Granada (UGR) and other institutions which the objective is the study of galaxies in voids. The main instrument used for the CAVITY objectives is the $3.5 \mathrm{~m}$ telescope and the PMAS fiber PAck (PMAS/PPak) instrument from Calar Alto located in Almería (Spain).
\end{abstract}

Using IFU data, already calibrated with the technique described by García-Benito et al. [2015] of the galaxies in voids selected by the CAVITY selection team, we have made a spectral study centered on $5600 \AA$, so we have created maps of signal, noise and signal/noise using the spectrum flux in the selected region. We have compared these maps with photometric data in the $\mathrm{g}$ band from the Sloan Digital Sky Survey project (SDSS, York et al. [2000]), the band closest to the spectrum chosen in the IFU data. With this we can make a comparison of signal, noise and signal/noise versus the flux of the SDSS data and make an exposure time calculator for the $3.5 \mathrm{~m}$ telescope and the Calar Alto PMAS/PPak instrument.

Next we have implemented a technique called Voronoi binning developed by Cappellari et al. [2003] with which we can group data obtained through spectral analysis and compare them with SDSS images through a simulator developed by Jesús Domínguez in his Master's Thesis on FISYMAT (2017, title: Preparing For The First Light Of WEAVE-Apertif). With this we got to make a comparative study of the data obtained by PMAS/PPak and the data obteined through the simulator.

Finally, we have carried out a simulation with 4866 galaxies in voids, the total of the CAVITY sample, to study the most optimal galaxies that we can observe with the $3.5 \mathrm{~m}$ telescope and the Calar Alto PMAS/PPak instrument, concluding that we have 1761 galaxies for the data collection with 1.5 hours of time exposure and 2577 galaxies with 3 hours.

Key words: survey, IFU, CAVITY, PMAS/PPak, Voronoi 


\section{Agradecimientos}

En primer lugar me gustaría agradecer a Isabel Pérez Martín por hacer posible que colabore en su proyecto. Gracias a ello he podido aprender muchísimo de galaxias y no solo de galaxias en vacíos.

Gracias Simon Verley por la infinita paciencia a la hora de enseñarme a programar Python. Nunca olvidare sus consejos aunque a veces no los siga y tenga que cambiar el código mil veces.

Muchísimas gracias a Jesús Domínguez Gómez que sin su ayuda a la hora de resolver problemas técnicos aun estaría simulando galaxias.

Gracias a todo el equipo de CAVITY por los conocimientos aprendidos en el "Midyear meeting" de CAVITY (Granada, 24 y 25 de Junio de 2021).

Por último pero no menos importante agradecer a $\mathrm{M}^{\mathrm{a}}$ Carmen Castellano Marín por su cariño y comprensión en los momentos bajos. 



\section{1 | Introducción}

Las primeras galaxias fueron identificadas en el siglo XVII por el astrónomo francés Charles Messier, que publicó en su famoso catálogo de cielo profundo, "The Catalog of Nebulae and Star Clusters", aunque en ese momento no sabía que eran galaxias.

Hubble [1926] encontró estrellas variables cefeidas en la nebulosa de Andrómeda. La variación de la luz de estas estrellas permitieron a Hubble determinar la distancia a la nebulosa utilizando la relación entre el periodo de las fluctuaciones de las cefeidas y su luminosidad. La estimación de la distancia colocó a la nebulosa de Andrómeda a aproximadamente 900.000 años luz de distancia. Si Hubble estaba en lo cierto, la nebulosa claramente se encontraba mucho más allá de la Vía Láctea. Por lo tanto, la nebulosa de Andrómeda tenía que ser una galaxia y no una nebulosa o un cúmulo de estrellas disperso dentro de la Vía Láctea. Los hallazgos de Hubble en la nebulosa de Andrómeda y en otras nebulosas espirales relativamente cercanas convencieron rápidamente a la gran mayoría de los astrónomos de que el universo se encuentra repleto de galaxias.

Pero las galaxias no se distribuyen de manera aislada en el universo sino que existen lo que conocemos como grupos de galaxias. Estos grupos consisten en galaxias agrupadas por la fuerza de gravedad, teniendo una población entre 50 y 100 galaxias en un diámetro de 1 a 2 megaparsec (Mpc), siendo 1 parsec(parallax of one arc second) el equivalente a 3.24 años luz. El grupo que contiene a nuestra galaxia, la Vía Láctea, es el llamado Grupo Local, que consta de unas 80 galaxias.

Cuando un grupo de galaxias supera estos 50-100 objetos lo denominamos cúmulo. Un cúmulo de galaxias puede albergar hasta miles de galaxias, en un diámetro de entre 1 y 5 megaparsec (Mpc) y se creía que era la mayor estructura del universo hasta la década de 1980 donde se descubrieron los supercúmulos de galaxias.

Los supercúmulos se conforman de cúmulos en los que cada elemento ya no es 


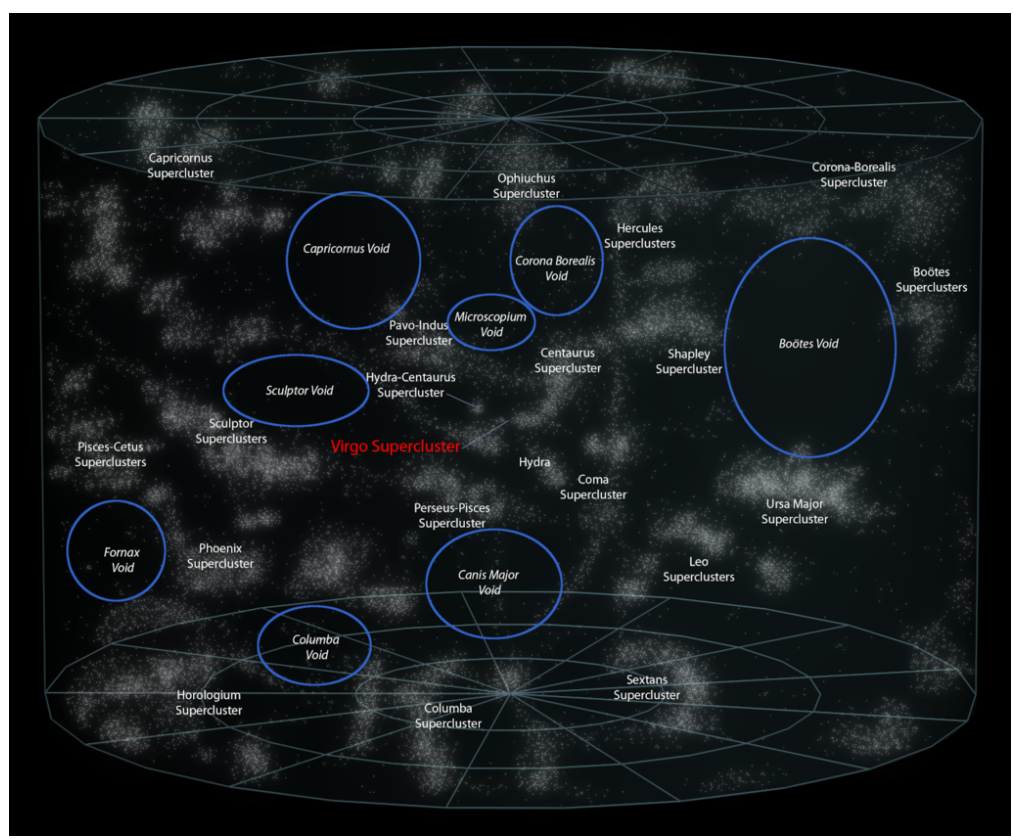

Figura 1.1: Un mapa de vacíos alrededor de filamentos. ${ }^{1}$ Podemos ver los vacíos rodeados en azul entre los supercúmulos representados en blanco. En rojo podemos ver el supercúmulo de Virgo que es donde se sitúa la Vía Láctea.

una galaxia sino un cúmulo.

El siguiente nivel en escala espacial se conoce como la estructura a gran escala del universo. Esta estructura se compone de muros, filamentos y vacíos, donde los supercúmulos se distribuyen a lo largo de las estructuras de estos filamentos y muros, quedando gran cantidad de regiones huecas, llamadas vacíos como podemos ver en la Figura 1.1. ${ }^{1}$

Las estructuras más grandes que conocemos son los filamentos galácticos, con un tamaño entre 50 y 80 megaparsec, gracias a Geller et al. [1989] que descubrieron la primera de estas estructuras y que se denominó "Great Wall".

En 2003 se descubrió una estructura mucho más grande, la "Sloan Great Wall" con 420 megaparsec, fue descubierta por Gott.III et al. [2005] gracias a los datos del telescopio de exploración digital del espacio Sloan.

La pared más grande descubierta recientemente fue en 2020 por Pomarède et al. [2020] y fue llamada "South Pole Wall" ya que forma un arco a lo largo del borde sur

\footnotetext{
${ }^{1}$ https://commons. wikimedia.org/w/index.php?curid=58212354.
} 


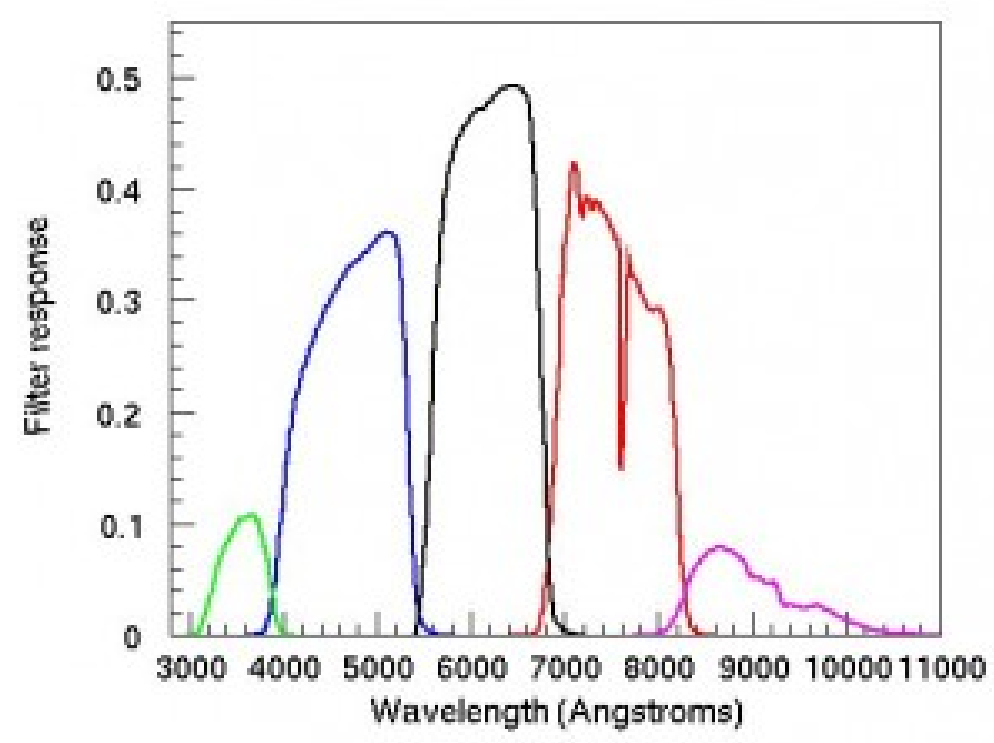

Figura 1.2: Curvas de rendimiento de los filtros de la cámara SDSS-III. ${ }^{2}$ De izquierda a derecha nos encontramos las bandas ultravioleta (u) a $3543 \AA$, verde (g) a $4770 \AA$, roja (r) a $6231 \AA$, infrarojo cercano (i) a $7625 \AA$ e infrarojo (z) a $9134 \AA$.

del cielo. Esta pared abarca una cantidad de 420 megaparsec de un extremo a otro, similar a "Sloan Great Wall".

El estudio del universo a gran escala ha sido posible gracias al catálogo Sloan Digital Sky Survey (SDSS), el primer catálogo digital en el rango óptico que cubría una gran parte del cielo.

La primera fase fue llevada a cabo entre los años 2000 y 2008 con el telescopio de 2.5 metros de diámetro en Apache Point Observatory en Nuevo México. La instrumentación se basaba en 30 cámaras $\mathrm{CCD}$, las cuales podían escanear una cuarta parte del cielo en cinco bandas fotométricas ( $\mathrm{u}, \mathrm{g}, \mathrm{r}, \mathrm{i}, \mathrm{z})$. Podemos ver el espectro de dichas bandas en la Figura 1.2. ${ }^{2}$

Un segundo instrumento, llamado espectrógrafo multi-objeto fue utilizado para la obtención de espectros centrales de varias galaxias al mismo tiempo, pudiendo observar hasta 640 espectros.

\footnotetext{
${ }^{2}$ https://www.sdss.org/instruments/camera/.
} 
Gracias al proyecto SDSS más de un millón de galaxias han sido observadas. Estos datos han sido publicados de forma libre en 16 publicaciones y a través de ellos, se han realizado artículos como el de Blanton et al. [2005] en el cual se hace un análisis en profundidad de propiedades físicas de las galaxias, como por ejemplo el color de las galaxias. Esta propiedad se estudia mediante el diagrama de color-magnitud de la galaxia que relaciona magnitud absoluta ${ }^{3}\left(M_{r}\right)$ con el índice de color ${ }^{4}$.

Podemos ver un ejemplo en la Figura 1.3 donde hay tres regiones diferenciadas; la secuencia roja , el valle verde y la nube azul. La secuencia roja incluye la mayoría de las galaxias rojas, que generalmente son galaxias elípticas, es decir galaxias viejas, grandes y masivas. La nube azul incluye la mayoría de las galaxias azules, que generalmente son espirales, es decir galaxias que tienen grandes cantidades de gas y polvo y que tienen una formación estelar activa. Entre las dos distribuciones hay un espacio subpoblado conocido como el valle verde que incluye una serie de espirales rojas. ${ }^{5}$

En el pasado, el estudio de espectros de SDSS se basaba como hemos visto en un solo espectro por galaxia. Actualmente se realiza lo que conocemos como espectrografía IFU (Integral Field Unit). Gracias a esta técnica podemos obtener un espectro de una galaxia entera, es decir, ya no solo de su centro, sino también de su estructura. Por lo tanto los datos IFU que obtenemos son cubos de imágenes, donde en dos ejes tenemos la posición de la galaxia y en un tercer eje tenemos el espectro de cada punto de la galaxia. Podemos ver un ejemplo de cómo es un cubo en la Figura 1.4. ${ }^{6}$

\subsection{Mapping Nearby Galaxies at APO (MaNGA)}

$\mathrm{MaNGA}^{7}$ es el proyecto SDSS más reciente que tiene como objetivo mapear la composición detallada y la estructura cinemática de 10,000 galaxias cercanas. MaNGA utiliza IFUs para poder analizar las propiedades de las galaxias.

\footnotetext{
${ }^{3}$ La magnitud absoluta de un objeto se define como la magnitud aparente que tendría el objeto si fuera visto desde una distancia de exactamente 10 parsecs, sin atenuación de su luz debido a la absorción interestelar, materia o polvo cósmico.

${ }^{4}$ Índice de color: diferencia entre dos medidas de magnitud de una estrella hecha en diferentes longitudes de onda.

${ }^{5}$ https://en.wikipedia.org/wiki/Galaxy_color \%E2 \%80\%93magnitude_diagram.

${ }^{6}$ https://www.sdss.org/dr14/manga/manga-tutorials/cubes-vs-rss/.

${ }^{7}$ Law and MaNGA Team [2014].
} 


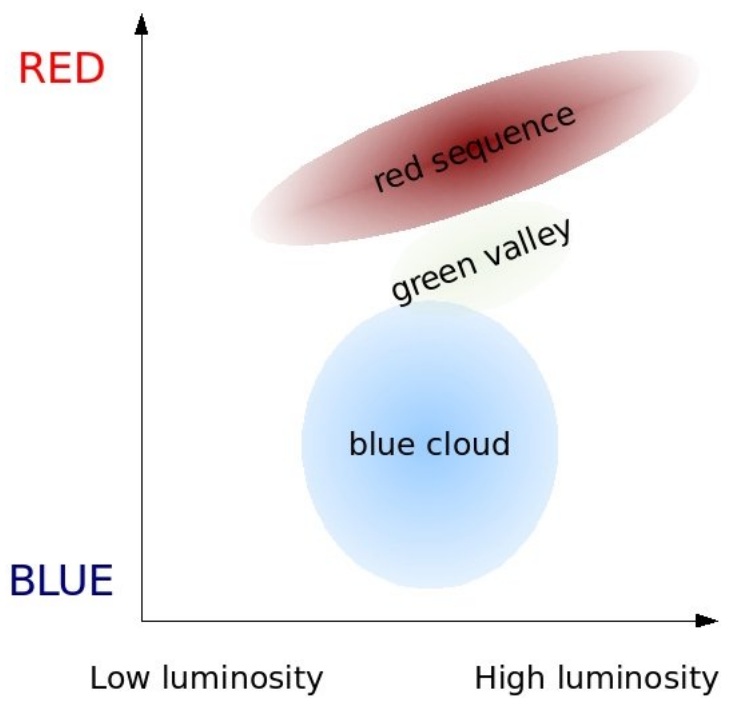

Figura 1.3: Diagrama color-magnitud para galaxias. ${ }^{5}$ En el eje de abcisas nos encontramos la magnitud absoluta, normalmente en la banda $\mathrm{r}$ y en el eje de ordenadas el color representado una diferencias entre bandas como puede ser g-r. Por lo tanto las galaxias se situarán en la secuencia roja, el valle verde o la nube azul dependiendo de su color.

Las IFUs de MaNGA son un grupo de fibras llamadas "bundles"8, en el que cada fibra individual produce un espectro. Debido a que las fibras son circulares, MaNGA o cualquier instrumento que utilice este tipo de fibras, necesita realizar lo que se conoce como "dithering", esto es tomar diferentes datos realizando pequeños movimientos entre la obtención de cubos de imagenes para poder llenar los huecos que hay entre las fibras.

A partir de los datos que obtenemos para cada fibra, resueltos espacialmente a través de la posición del objeto (RA / DEC), podemos generar una imagen en la parte del espectro que queramos.

\subsection{Nuestro objetivo}

El objetivo de este trabajo es llevar a cabo un estudio de la calidad de los datos que se pueden obtener con un instrumento IFU particular: PMAS/PPak situado en

\footnotetext{
${ }^{8}$ https://www.sdss.org/dr14/manga/.
} 


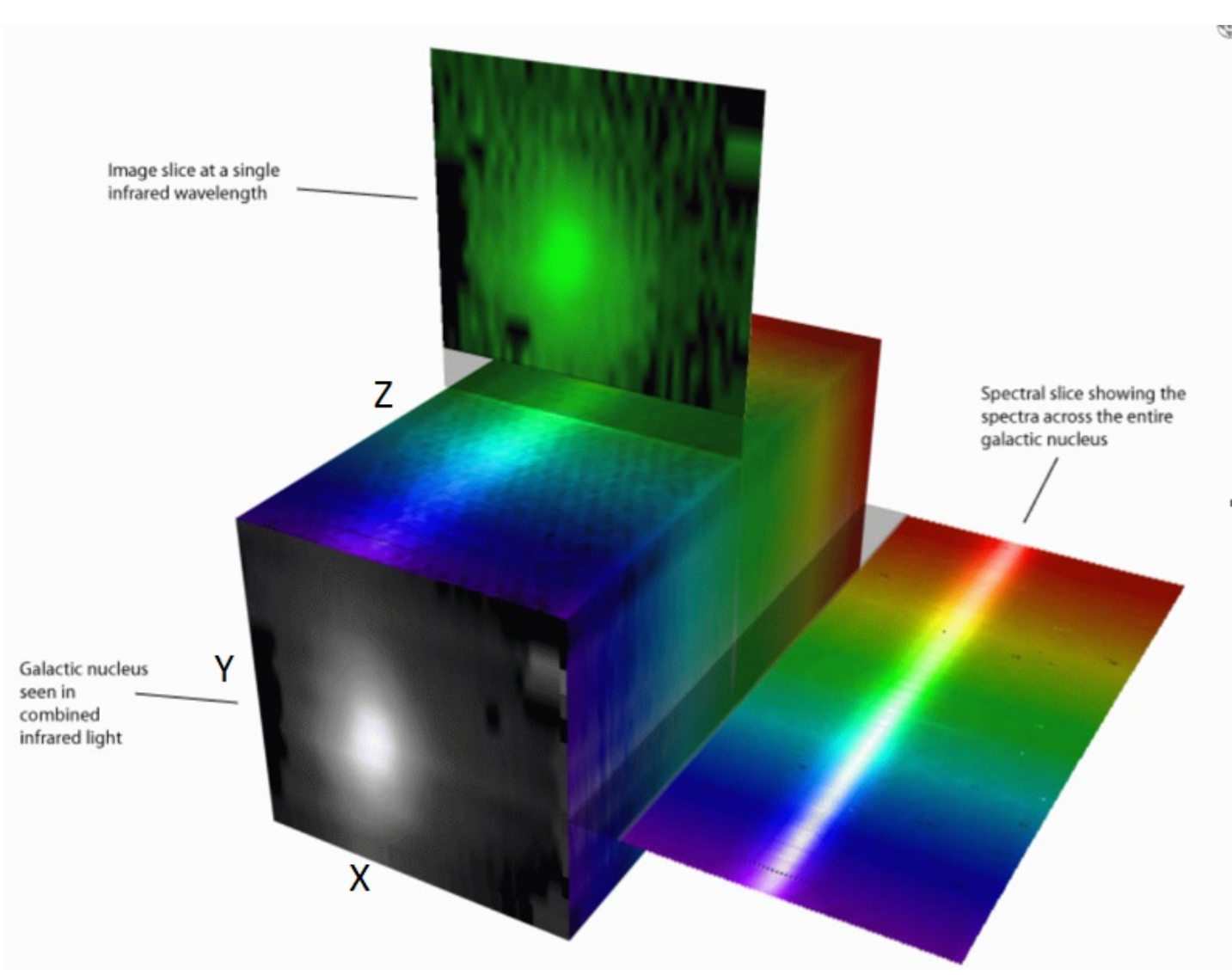

Figura 1.4: Ejemplo de un cubo. ${ }^{6}$ Esta sería la estructura que tendría un cubo de imágenes, podemos ver como podemos crear diferentes imágenes dependiendo de la parte del espectro que elijamos, en el caso de la figura se elige una longitud de onda infrarroja. También se puede ver el espectro del núcleo en la parte derecha de la imagen. Por lo tanto tendriamos la posicion de la galaxia en coordenadas (RA, DEC) en los ejes $\mathrm{X}$ e $\mathrm{Y}$ y en el eje $\mathrm{Z}$ nos encontramos un espectro con longitud de onda $\lambda$. 


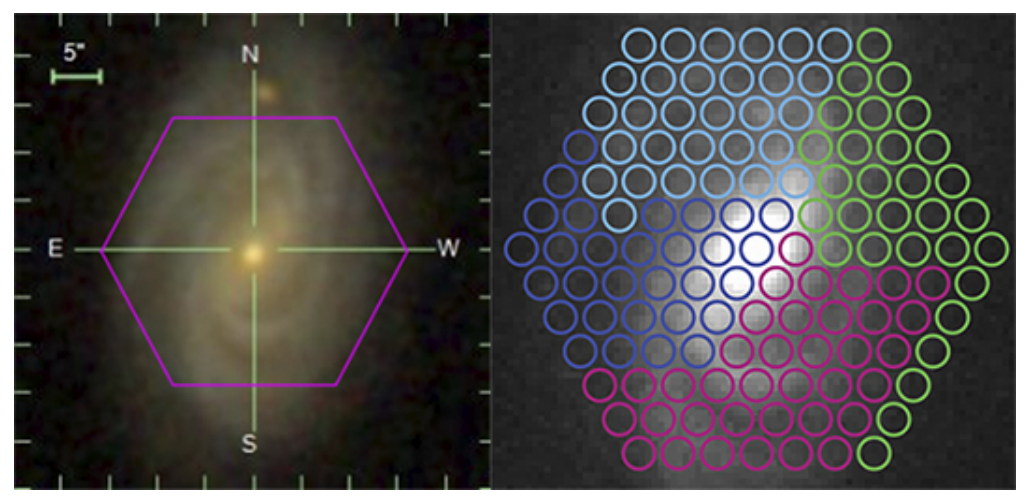

Figura 1.5: Izquierda: una galaxia espiral vista por MaNGA; el hexágono morado muestra el campo del instrumento IFU de MaNGA . Derecha: la misma galaxia espiral pero con las fibras IFU individuales, en donde podemos ver los huecos que se quedan sin señal entre dichas fibras circulares. ${ }^{8}$

el telescopio de $3.5 \mathrm{~m}$ de Calar Alto en Almería. Este estudio se va a llevar a cabo dentro del proyecto internacional CAVITY (Sección 1.3). Para ello vamos a analizar parámetros de calidad de la imagen simulando las observaciones IFU de PMAS/PPak usando imágenes del cartografiado de SDSS como input a los modelos. Como resultado obtendremos los tiempos de exposición necesarios para obtener datos fiables de cada objeto de la muestra de CAVITY y nos ayudará a deshechar objetos de la muestra para los cuales no se pueden obtener datos de la calidad necesaria para cumplir los objetivos científicos el proyecto.

\subsection{Calar Alto Void Integral-field Treasury surveY (CA- VITY)}

Este trabajo está encuadrado en el proyecto internacional Calar Alto Void Integralfield Treasury surveY ${ }^{9}$. CAVITY es uno de los proyectos de legado de los próximos años del observatorio de Calar Alto en Almería. Los objetivos del proyecto son los siguientes:

1. Determinar cómo ha influido la materia bariónica y oscura en las galaxias en vacios cósmicos.

\footnotetext{
${ }^{9}$ https://cavity.caha.es/.
} 
2. Establecer cómo la formación de galaxias y sus propiedades dependen del entorno a gran escala.

3. Encontrar el principal impulsor de la transformación de las galaxias, desde la formación de estrellas hasta los sistemas pasivos o inactivos en los vacíos.

La instrumentación utilizada para lograr estos objetivos es el telescopio de 3,5 metros de Calar Alto y PMAS/PPak, un interferómetro que utiliza fibras circulares con las que podemos construir una imagen tridimensional, es decir un cubo.

Como vimos en la Sección 1.1 vamos a generar un espectro por cada coordenada de la galaxia. En una imagen convencional, cada fotodetector equivale a un píxel (picture element) y en cada píxel se almacena un valor de brillo. En un cubo lo llamamos spaxel (spectral pixel), esto es equivalente a un píxel pero con un espectro en lugar de un solo valor. Por tanto, el cubo que obtendremos tendrá el aspecto de una imagen con un eje adicional, es decir, en los metadatos de la imagen tendremos información no solo de un valor sino de un espectro en cada coordenada.

En este trabajo realizaremos un análisis para la futura selección de galaxias que podemos estudiar a través de:

1. Inspección de catálogos: partimos del catálogo Pan et al. [2012] con alrededor de 80000 galaxias en vacíos, con datos recopilados del catálogo SDSS. Cruzaremos este catálogo con el catálogo de MaNGA con aproximadamente 10000 galaxias.

2. Utilizando los datos recopilados hasta ahora mediante el telescopio de Calar Alto, analizaremos cómo cambia la señal y el ruido en comparación con el brillo superficial y el tiempo de exposición, para así poder realizar una calculador del tiempo de exposición y ver a qué magnitud podemos llegar.

3. Bineado de Voronoi: realización de un bineado de Voronoi, tanto para los cubos obtenidos en Calar Alto como para imágenes del catálogo SDSS a través de una simulación en la que seleccionaremos las mejores galaxias para ser estudiadas.

\subsubsection{Catálogo de Pan et al. [2012]}

El cartografiado de Sloan supuso una revolución en el estudio de la distribución de las galaxias en el universo, lo que se conoce como las estructuras a gran escala y que 


\begin{tabular}{ccc} 
Pan & MaNGA & Voids \\
\hline 79947 & $\sim 1600$ & $\sim 1000$ \\
$\sim 8000$ & 345 & 42 \\
$\sim 4000$ & 204 & 15
\end{tabular}

Tabla 1.1: Número de galaxias y vacíos en diferentes submuestras.

derivó en catalogar objetos de diferentes estructuras. El proyecto CAVITY ha elegido las galaxias de su muestra de un catálogo llevado a cabo por Pan et al. [2012].

El artículo de Pan et al. [2012] cuenta con 79947 galaxias distribuidas en vacios. Esta cantidad de galaxias son demasiadas para un estudio de datos IFU mediante un telescopio de clase $3.5 \mathrm{~m}$ como el telescopio de Calar Alto, ya que cada galaxia lleva un tiempo medio de integración de 2 horas, lo que hace imposible llevar a cabo observaciones de este tipo para una muestra tan amplia. Debido a esto el equipo de CAVITY está creando un catálogo más adecuado para alcanzar los objetivos científicos mediante la instrumentación disponible.

En este contexto hemos trabajado con diferentes catálogos para realizar el nuestro propio. Comenzamos con el catálogo de Pan et al. [2012]. En este catálogo podemos encontrar 79947 galaxias. El siguiente catálogo con el que trabajamos es con el catálogo de MaNGA, que cuenta con aproximadamente 1600 galaxias distribuidas en diferentes vacíos. Por lo tanto tenemos por un lado datos astronómicos en las bandas Sloan gracias al SDSS de 79947 galaxias catalogadas por Pan et al. [2012] y datos IFU gracias a MaNGA de $\sim 1600$ galaxias que se encuentran dentro de las 79947 galaxias de SDSS.

Finalmente el equipo de selección de CAVITY hizo una primera selección de 8000 de galaxias del catálogo elaborado por Pan et al. [2012], las cuales se encontraban distribuidas en 42 vacíos. De estas $~ 8000$ galaxias, en el catalogo de MaNGA habían sido observadas 345 . De estos 42 vacíos se hizo una segunda selección en la que nos quedamos con 15 vacíos, en los que tenemos unas 4000 galaxias en el catalogo de Pan et al. [2012] y 204 de estas $~ 4000$, que ya han sido observadas por MaNGA. Podemos ver estos números en la Tabla 1.1 


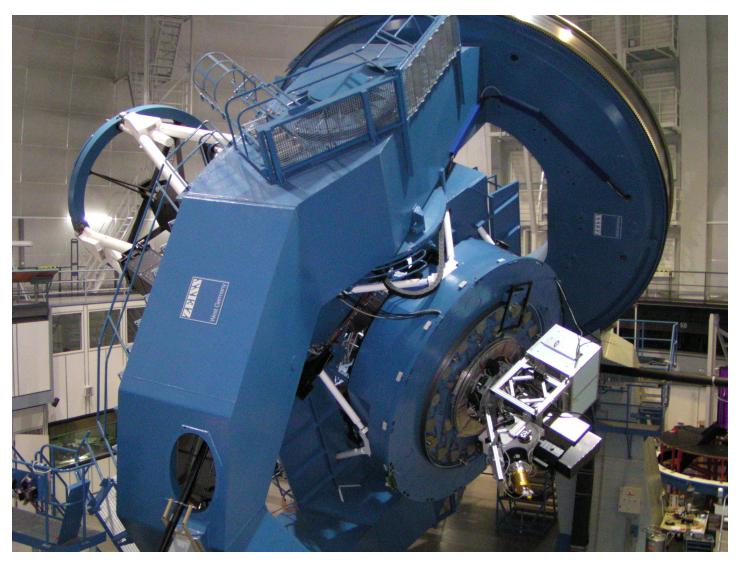

Figura 1.6: El instrumento PMAS junto con el telescopio de 3,5 m en Calar Alto, permite al observador obtener imágenes y espectros simultáneamente. ${ }^{10}$

\subsubsection{PMAS fiber PAck (PPak)}

PMAS/PPak es el principal instrumento que usa CAVITY junto con el propio telescopio de 3.5 metros de Calar Alto para obtener la espectroscopía de galaxias. Este instrumento proporciona espectros para cada punto del espacio, por lo tanto podemos obtener datos IFUs de galaxias.

Antes de PMAS/PPak, el instrumento que utilizaba Calar Alto era PMAS (Potsdam Multi-Aperture Spectrophotometer), un espectrofotómetro que cubre un rango de longitudes de onda desde el ultravioleta al infrarrojo cercano, pero que solo puede registrar 256 espectros al mismo tiempo y su campo de visión está limitado a $16 \times 16$ segundos de arco. El instrumento PMAS $^{10}$ se instaló en el telescopio de 3,5 m en Calar Alto, el cual puede obtener datos IFUs mediante el uso de fibras ópticas, que guían la luz desde el plano focal del telescopio a un espectrógrafo de alto rendimiento, podemos ver parte del telescopio y del instrumento PMAS de Calar Alto en la Figura 1.6.

El estudio de galaxias requirió espectroscopía de imágenes a mayor resolución espectral. En el Instituto Leibniz de Astrofísica de Potsdam (AIP), se diseñó y construyó un haz de fibras especializado, PMAS/PPak. Esta nueva unidad de campo integral comenzó a obtener datos a partir del 1 de enero de 2004.

PMAS/PPak presenta un paquete hexagonal central con 331 fibras ópticas para

\footnotetext{
${ }^{10}$ https://www.aip.de/highlight_archive/kelz_ppak/index.html.
} 


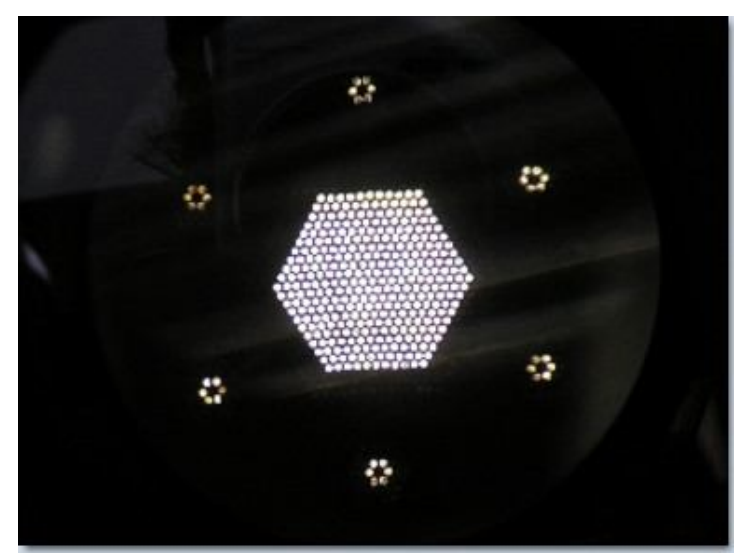

Figura 1.7: Haz de fibra PMAS/PPak con 331 fibras densamente empaquetadas, forman la unidad de campo integral del hexagonal central y 36 fibras adicionales rodean el centro IFU para la calibración. ${ }^{10}$

muestrear un objeto a 2,7 segundos de arco por fibra, con un campo de visión de $74 \times 65$ segundos de arco. Con esta resolución el objetivo de PMAS/PPak no es la resolución espacial sino más bien poder captar objetos astronómicos con un bajo brillo superficial como galaxias débiles.

\subsection{Simulador de datos IFU}

A la hora de realizar el bineado de Voronoi ${ }^{11}$ en los cubos de imágenes que obtenemos con PMAS/PPak necesitamos una referencia con datos de otras imágenes para así poder hacer una comparación. Esto lo conseguimos mediante un simulador que utiliza la técnica de bineado de Voronoi creado por Cappellari et al. [2003], que resuelve de manera óptima el problema de preservar la máxima resolución espacial de los datos bidimensionales, dada una restricción en la relación mínima señal/ruido.

El bineado de Voronoi nos ayudará a agrupar spaxels para poder obtener una señal/ruido suficiente para el análisis de las poblaciones estelares de las galaxias ${ }^{12}$ en

\footnotetext{
${ }^{11}$ El diagrama de Voronoi de un conjunto de puntos en el plano es la división de dicho plano en regiones, de tal forma, que a cada punto se le asigna una región del plano formada por los puntos que son más cercanos a él. A estas divisiones las llamaremos bines.

${ }^{12}$ Un grupo de estrellas dentro de una Galaxia que se parecen entre sí en distribución espacial, composición química o edad se denomina población estelar.
} 
vacíos.

El simulador que hemos utilizado para realizar un bineado de Voronoi ha sido el realizado por Jesús Domínguez en su trabajo de Fin de Máster de FISYMAT (2017, título: Preparing For The First Light Of WEAVE-Apertif). Este simulador, mediante un programa llamado SEXTRACTOR, nos permite conocer a través de la fotometría de imágenes de galaxias de SDSS, la inclinación y semiejes de la isofota ${ }^{13} 24$ mag $\operatorname{arcsec}^{-2}$. Posteriormente utiliza un calculador de tiempo de exposición que relaciona el brillo superficial de un objeto con la señal y el ruido del espectro que se obtendría al observarlo con un IFU. El brillo superficial se deriva a partir de las imágenes de SDSS. Finalmente realiza el bineado de Voronoi de la galaxia indicada.

Dentro de este simulador nos encontramos un scrip que descarga las imágenes a través del servidor SDSS. Una vez que tenemos estas imágenes el simulador a través de una serie de parámetros como por ejemplo la señal/ruido a la que queremos llegar, realiza una máscara en la que se aplicará el bineado de Voronoi.

Hemos ajustado el calculador de tiempo de exposición que usa este simulador para que replique la sensibilidad del instrumento PMAS/PPak. Esto lo hemos hecho relacionando el brillo superficial de imágenes de SDSS con cubos reales obtenidos con dicho instrumento. Este procedimiento se explica más extensamente en la Sección 2.2.4.

El simulador necesita una tabla en formato fits con el nombre de la galaxia que queremos observar, en nuestro caso elegimos CAVITY y las coordenadas del objeto en grados.

El simulador nos arroja una tabla en formato fits donde podemos encontrar parámetros como el número de bins pero también los semiejes, inclinación, el ángulo de posición (PA) y radio máximo en arcmin de la elipse que ajusta la galaxia. También obtenemos las imágenes de todas las galaxias en la banda seleccionada, una gráfica con el perfil de brillo y el bineado de cada galaxia.

\footnotetext{
${ }^{13}$ Isofota: una curva en un mapa que une puntos de igual intensidad de luz de una fuente determinada.
} 


\section{Caracterización de la señal/ruido (SN) en los cubos de PMAS/PPak}

En este capítulo abordamos la relación del brillo superficial ${ }^{1}$ de las imágenes de SDSS con el tiempo de exposición, señal y ruido ${ }^{2}$ espectral de los cubos de PMAS/PPak.

Esto nos ayudará a hacer un calculador de señal y ruido espectral a partir del brillo superficial y tiempo de exposición, que usaremos en la Sección 3 para predecir las galaxias que serán apropiadas para futuras observaciones en cuanto a SN.

\subsection{Preparación de los cubos}

\subsubsection{Introducción}

Los datos que obtenemos de PMAS/PPak se tratan previamente para corregir efectos instrumentales, esto es: calibración a través de sustracción de bias y dark, limpieza de rayos cósmicos, spectra tracing, compensación por flexiones en el tren óptico, extracción de espectros, correcciones de campo uniforme a través de flats, y calibración de longitud de onda. Este tratamiento se lleva a cabo como el realizado por GarcíaBenito et al. [2015].

Además de esta calibración, al realizar las capturas se realiza un dithering para evitar dejar huecos entre cada fibra. Esto se debe a que las fibras son circulares y hay

\footnotetext{
${ }^{1}$ El brillo superficial (SB) cuantifica la densidad de flujo por unidad de área angular de un objeto, especialmente extenso en el cielo como una galaxia o nebulosa.

${ }^{2}$ Consideramos señal como la mediana del flujo del espectro de todos los spaxel en la banda [5550$5650 \AA$ A] y el ruido como la desviación estándar en dicha banda.
} 
áreas donde no se recolecta luz, por lo que movemos el telescopio entre tomas para cubrir estas regiones como podemos ver en el artículo realizado por García-Benito et al. [2015]. Debido a esto, debemos hacer una interpolación en los cubos cuando hagamos la reducción ya que algunas áreas tendrán más exposición que otras debido a que han tenido más tiempo de exposición por spaxel.

En este trabajo hemos usado cubos de imágenes ya calibradas.

\subsubsection{Obtención de mapas de SN}

Desde los metadatos de los cubos obtenidos en formato fits utilizaremos los siguientes parámetros:

1. CRVAL1, CRVAL2, CRVAL3: valor del spaxel de referencia en RA, DEC y $\lambda$ respectivamente;

2. CRDEL1, CRDEL2, CRDEL3: distancia entre los spaxel del cubo en RA, DEC y $\lambda$ respectivamente;

3. CRPIX1, CRPIX2, CRPIX3: índice de posición del spaxel de referencia en RA, DEC y $\lambda$ respectivamente.

Con estos valores y con el cubo vamos a obtener una SN por spaxel, que guardaremos en una matriz. Lo que haremos es calcular la señal como la media del espectro en una región centrada en $\lambda=5600 \AA$ con una separación de $\pm 50 \AA$ y el ruido como desviación estándar de la misma región.

También debemos hacer una corrección de redshift (corrimiento al rojo), ya que el espectro observado está desplazado, por lo que aplicamos la siguiente fórmula para corregir este desplazamiento:

$$
\frac{\lambda_{\mathrm{obs}}}{\lambda_{\mathrm{emi}}}=1+z
$$

donde $\mathrm{z}$ es el redshift.

Por tanto, tendremos una región de $\lambda_{k} \in[5500 \AA, 5650 \AA]$ en la que buscaremos señal y ruido: 


$$
\begin{aligned}
\text { Señal }[i, j] & =\frac{\sum_{\text {Número de píxel inicial }}^{\text {Número de píxel final }} \text { flujo }\left(\lambda_{k}\right)}{\text { Número de píxel }} \\
\text { Ruido }[i, j] & =\frac{\sum_{\text {Número de píxel final }}^{\text {Núxel inicial }} \text { flujo }\left(\lambda_{k}\right)-\overline{\text { flujo }\left(\lambda_{k}\right)}}{\text { Número de píxel }-1} .
\end{aligned}
$$

donde $[i, j]$ son las posiciones de cada spaxel del cubo. El número de píxel inicial es el valor de píxel donde $\lambda_{\text {initial }}=5550 \AA$ y el píxel final corresponde a $\lambda_{\text {final }}=5650 \AA$. De esta forma a vamos a generar una imagen en la que ya tenemos un valor por cada coordenada de nuestro cubo, por lo que ya tenemos un píxel y no un spaxel.

En la primera imagen de la Figura 2.1 podemos ver un mapa de SN de todo el cubo de la galaxia CAVITY17344 en $\lambda=5600 \AA ̊$ y en la segunda imagen de la Figura 2.1 podemos ver el espectro del spaxel central, así como la región de interés en la que hemos medido la señal y el ruido.

\subsubsection{Obtención de las coordenadas de todos los píxeles de los mapas de señal ruido}

Para realizar la fotometría de cada píxel en las imágenes SDSS necesitamos las coordenadas RA y DEC de cada spaxel del cubo, con el fin de tener el mismo punto en el cielo en las imágenes SDSS a las que vamos a aplicar la fotometría.

Por lo tanto, usando CRVAL CRDELT y CRPIX de RA, DEC vamos a construir una matriz en la que cada elemento i será RA y j será DEC.

Para ello calculamos el valor mínimo y máximo de coordenadas en RA y DEC como:

$$
\begin{aligned}
\min _{\mathrm{DEC}} & =\mathrm{CRVAL}_{2}-\left(\mathrm{CRPIX}_{2}-1\right) \times \mathrm{CDELT}_{2} \\
\max _{\mathrm{DEC}} & =\min _{\mathrm{DEC}}+\text { número de spaxel en } \mathrm{DEC} \times \mathrm{CDELT}_{2} . \\
\min _{\mathrm{RA}} & =\mathrm{CRVAL}_{1}-\mathrm{CRPIX}_{1} \times \frac{\mathrm{CDELT}_{1}}{\cos (\mathrm{DEC})} \\
\max _{\mathrm{RA}} & =\min _{\mathrm{RA}}+\text { número de spaxel en RA } \times \frac{\mathrm{CDELT}_{2}}{\cos (\mathrm{DEC})}
\end{aligned}
$$



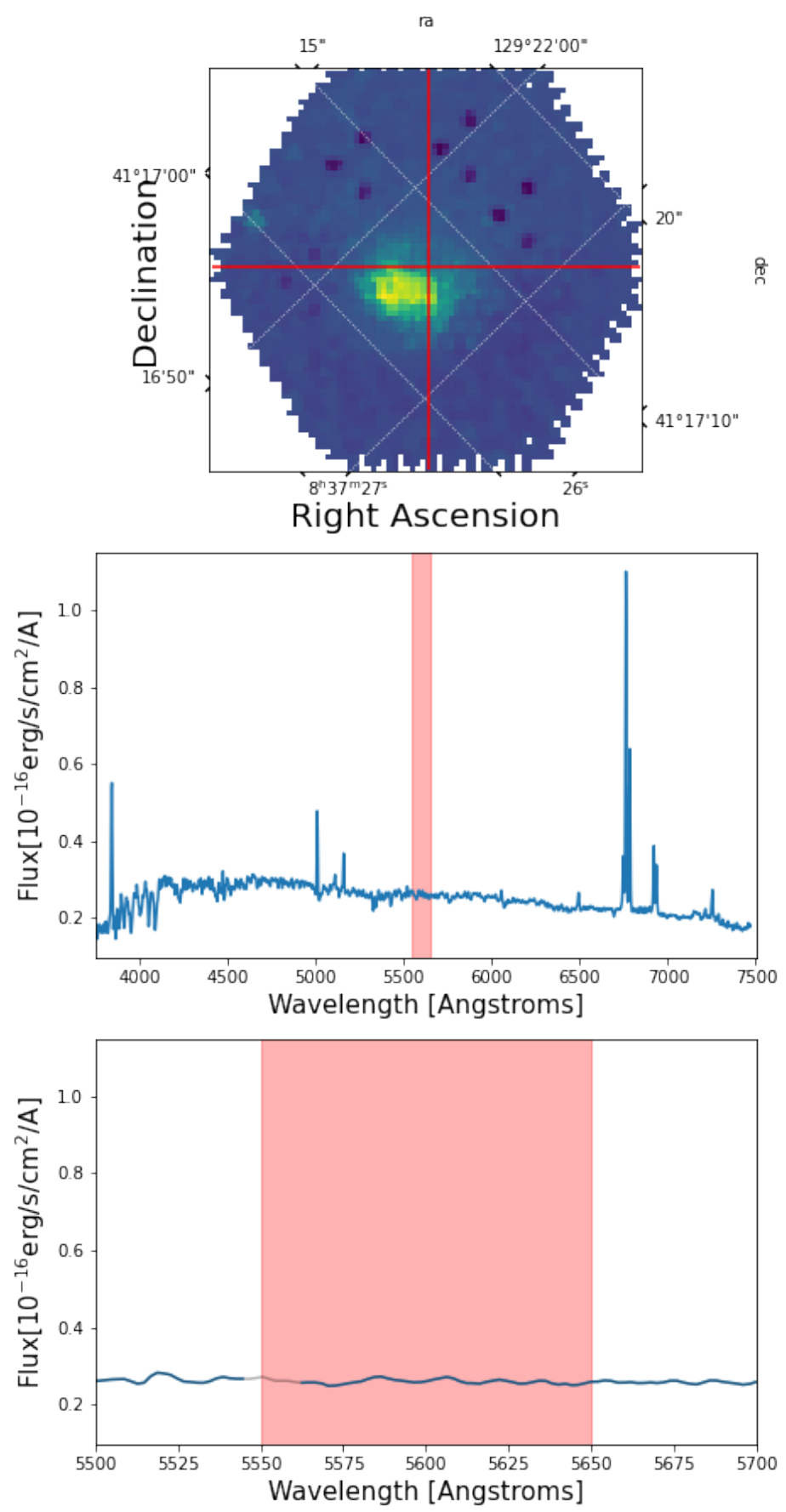

Figura 2.1: Mapa de SN y espectro de CAVITY17344 en el spaxel central. En la primera imagen representamos un mapa de SN con la referencia del spaxel central, esto se indica con la cruceta roja. En la segunda imagen señalamos todo el espectro y la región que nos interesa de $\pm 50 \AA$ A La última imagen es un zoom en la región en la que medimos el flujo, donde hemos enmascarado la región del espectro que introduce una linea de cielo. 
Con esto nos aseguramos de pasar por todos los spaxels ya que tenemos el valor del spaxel central y conocemos el valor en RA y DEC de la separación entre los spaxels.

Para las coordenadas de RA debemos tener en cuenta la corrección de cos(DEC) ya que las coordenadas ecuatoriales son una proyección de una esfera en el cielo, por lo tanto, si a partir del ecuador $\left(\mathrm{DEC}=0^{\circ}\right)$ nos movemos hacia el polo norte $\left(\mathrm{DEC}=90^{\circ}\right)$ RA disminuirá con respecto al valor real y como queremos hacer proyecciones del spaxel en las imágenes SDSS, debemos aplicar esta corrección.

\subsection{Simulación de datos PMAS/PPak con imágenes de SDSS.}

En esta sección haremos una correlación entre los píxeles de los mapas SN generados por los cubos de PMAS/PPak y los píxeles ya calibrados de las imágenes de SDSS para así poder hacer un estudio de $\mathrm{SN}$ frente al brillo superficial.

\subsubsection{Descarga de imágenes de SDSS.}

Lo primero que hacemos es descargar los archivos fits de SDSS correspondientes a las galaxias que tenemos en nuestros cubos de CAVITY. Para ello usaremos un scrip de Python en el que daremos como entrada el nombre de las galaxias de CAVITY y su posición en RA y DEC respectivamente. Las imágenes fits se verán como la imagen izquierda de la Figura 2.3

Una vez descargados los archivos realizaremos el proceso de fotometría.

\subsubsection{Proceso de fotometría en imágenes SDSS utilizando el tamaño del spaxel del cubo}

Para realizar la fotometría vamos a utilizar el tamaño del spaxel del cubo, es decir, $1 \times 1 \operatorname{arcsec}^{2}$. Por tanto, vamos a calcular la cantidad de luz que integra un spaxel en la imagen SDSS. Esta magnitud se dará en nanomaggies(nMgy), una unidad característica del catálogo SDSS ${ }^{3}$, que transformaremos a mag $\operatorname{arcsec}^{-2}$ como :

\footnotetext{
${ }^{3}$ https://www.sdss.org/dr12/algorithms/magnitudes/.
} 


$$
\mathrm{m}=22.5[\mathrm{mag}]-2.5 \times \log _{10}(\mathrm{~F}[\text { nanomaggies }])
$$

donde $\mathrm{F}$ es el flujo de un objeto dado en nMgy y m la magnitud aparente. Dado que la apertura que estamos tomando es de 1 segundo de arco cuando calculamos el brillo superficial (SB) obtenemos:

$$
\begin{aligned}
\mathrm{SB} & =-2.5 \times \log \left(\frac{F}{F_{0} A^{2}}\right)=-2.5 \times\left(\log \frac{F}{F_{0}}-\log \times\left(A^{2}\right)\right) \\
& =m+2.5 \log \left(A^{2}\right)
\end{aligned}
$$

siendo A la apertura, es decir, el área donde se recolecta la luz en unidades de $\operatorname{arcseg}^{2}$. Como la apertura es de $1 \operatorname{arcseg}^{2}, 2.5 \times \log _{10}\left(\mathrm{~A}^{2}\right)=0 \rightarrow \mathrm{SB}=\mathrm{m}$. Por tanto ya tenemos una correspondencia spaxel-SB con la que también tendremos una relación entre píxel-SB en los mapas creados de señal, ruido y señal/ruido.

\subsubsection{Comprobación de la imagen SDSS con aperturas de cubos de PMAS/PPak}

Una vez realizada la fotometría de los spaxels del cubo en las imágenes SDSS, vamos a comprobar que lo hemos hecho correctamente. Para ello vamos a representar los spaxels en píxeles en las imágenes SDSS.

Partiremos de la Figura 2.2 donde tendremos todos los píxeles del mapa de SN que representa el cubo de PMAS/PPak.

Estas aberturas cuadradas de $1 \times 1 \operatorname{arcseg}^{2}$ serán llevadas a las imágenes SDSS para hacer la fotometría como podemos ver en la imagen derecha de la Figura 2.3.

Por lo tanto hemos realizado la fotometría en la imagen SDSS con los mismos parámetros que tenemos en los mapas de $\mathrm{SN}$, de tal manera que podemos hacer una correspondencia de la señal, ruido y SN de los cubos con el brillo superficial de las imágenes SDSS.

Finalmente en la Figura 2.4 podemos ver la imagen de SDSS una vez que hayamos tomado las aberturas del cubo de $1 \operatorname{arcseg}^{2}$. 


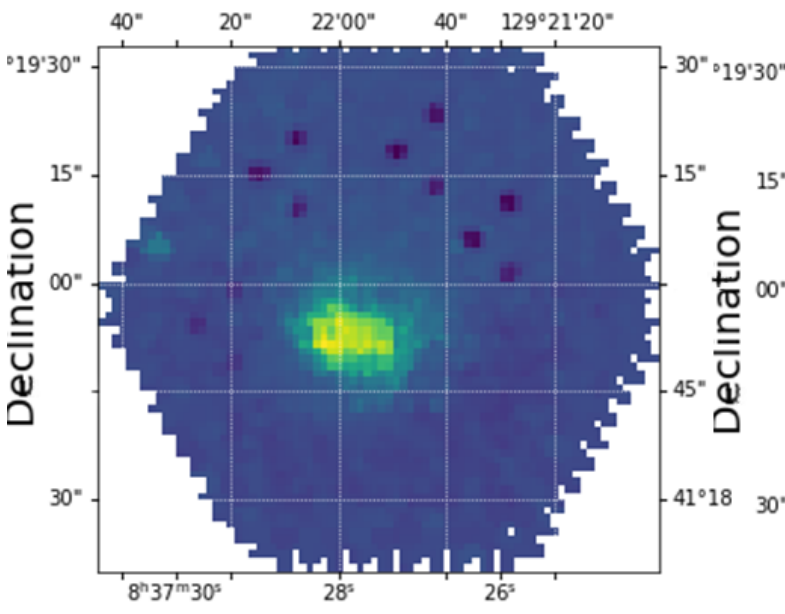

Right Ascension

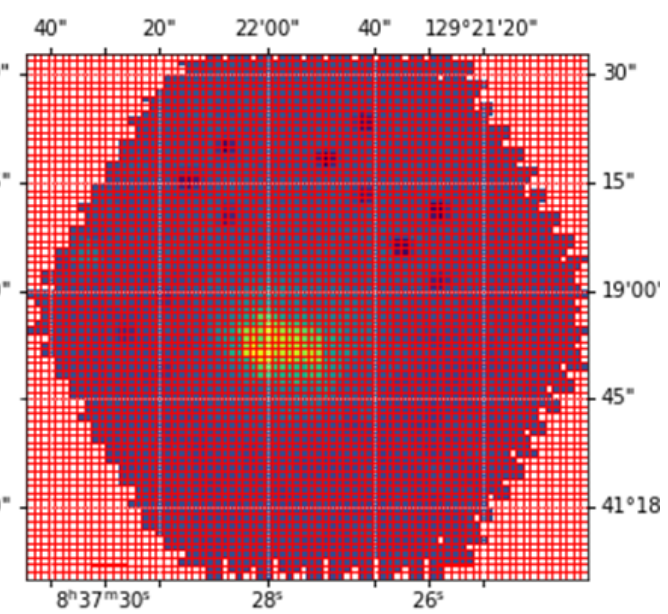

Right Ascension

Figura 2.2: Izquierda: mapa de SN de la galaxia CAVITY17344 en PMAS/PPak. Derecha: aperturas de los spaxel de 1x1 $\operatorname{arcseg}^{2}$ de CAVITY17344 en PMAS/PPak.

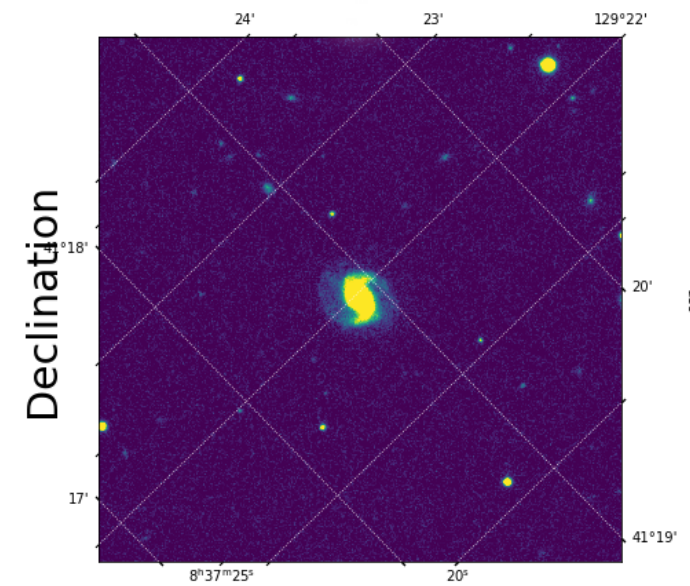

Right Ascension

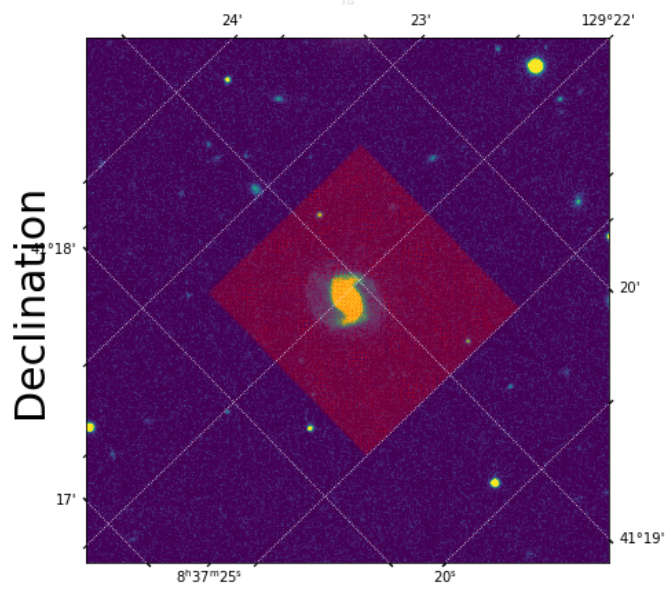

Right Ascension

Figura 2.3: Izquierda: imagen en SDSS de la galaxia CAVITY17344. Derecha: aperturas de los spaxel de $1 \times 1$ arcseg de CAVITY17344 en la imagen SDSS. 
28 ESTUDIO DE GALAXIAS EN VACíOS MEDIANTE ANÁLISIS DE DATOS IFU

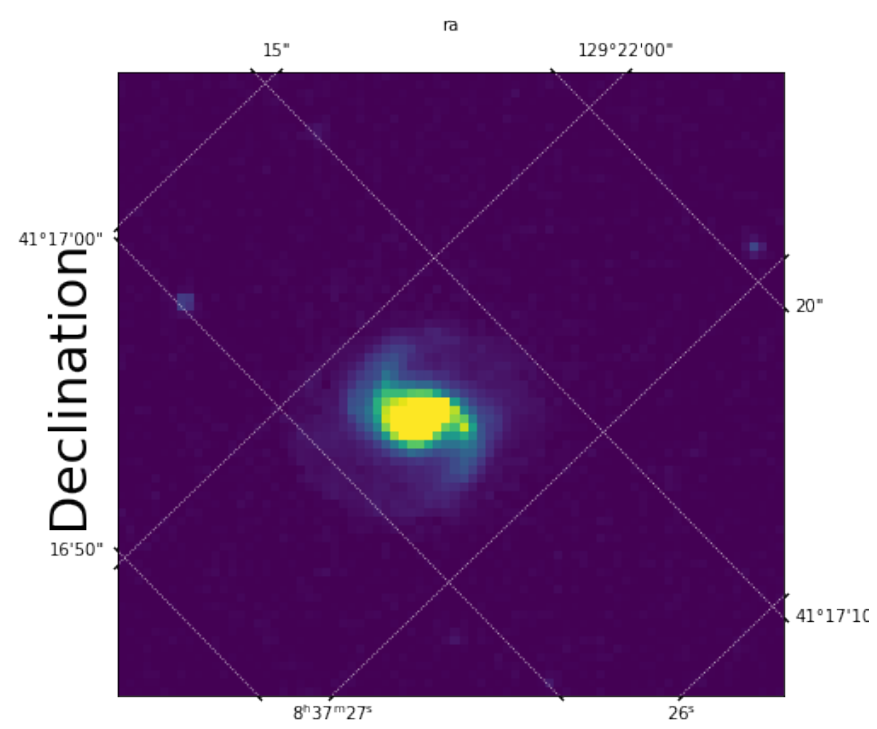

Right Ascension

Figura 2.4: CAVITY17344 en SDSS con la resolución final de PMAS/PPak. Podemos apreciar como los píxeles son mas grandes ya que los hemos aumentado en un factor de 2.5 aproximadamente al realizar la fotometría con la apertura de PMAS/PPak. 


\subsubsection{Resultados obtenidos con la fotometría de imágenes SDSS}

Para realizar los mapas de SN utilizamos la señal en una banda de espectro de $\lambda=5600 \pm 50 \AA$ de tal forma que no tomemos ninguna línea de emisión o absorción de la galaxia.

A través del estudio del espectro elegido, vimos que una línea de cielo entraba en nuestro análisis. En un principio dejamos esta línea porque creíamos que no afectaría demasiado a los datos, pero al tomar el ruido como la desviación estándar, ese pico provocó que la SN variara mucho de un cubo a otro. Dicha línea se encontraba en [5530 $\AA-5565 \AA$ ], es decir al inicio de la banda escogida, por lo que hemos enmascarado esta línea. Finalmente, medimos la señal como la mediana y el ruido como la desviación estándar usando la función sigma-clipping ${ }^{4}$.

Una vez que tenemos la señal, el ruido y la SN de los cubos PMAS/PPak emparejados con el brillo superficial de las imágenes SDSS, podemos comenzar a representar uno frente a otro.

\section{SN frente a brillo superficial}

Analizamos la SN en función del brillo superficial de tal forma que obtuvimos hasta que magnitud podemos tomar la señal como válida, es decir una SN mayor que 3.

Como podemos ver en la Figura 2.5 tenemos que para una SN mayor que 3, el brillo superficial está en 25 mag $\operatorname{arcseg}^{-2}$ así que tendremos esto en cuenta al ajustar los datos.

\section{Señal frente al brillo superficial}

Necesitamos obtener una curva que se ajuste a todos los datos de todas las galaxias obtenidas por PMAS/PPak. Para ello tendremos que realizar un ajuste de los datos de cada cubo y luego realizar una mediana de cada parámetro que ajuste dichas datos, obteniendo un ajuste final de todos los cubos.

\footnotetext{
${ }^{4}$ función sigma-clipping: es un función que nos da la media, mediana y desviación estándar de los datos que están menos dispersos.
} 
30 ESTUDIO DE GALAXIAS EN VACÍOS MEDIANTE ANÁLISIS DE DATOS IFU

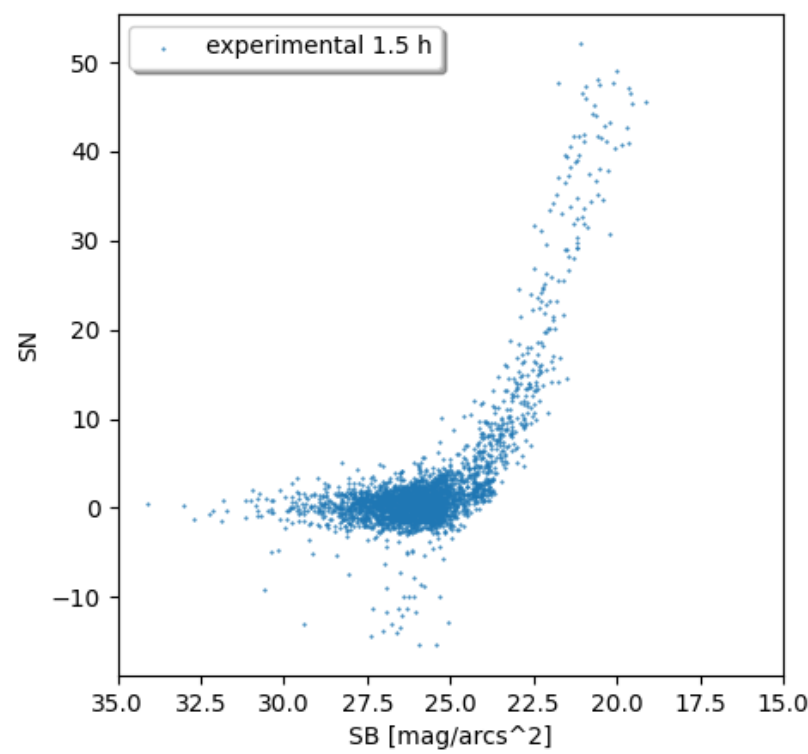

Figura 2.5: SN frente a brillo superficial para CAVITY17344. Vemos una tendencia exponencial de la SN frente al brillo superficial. Los datos con una SN mayor que 3 se situan por encima de un brillo superficial de $25 \mathrm{mag} \mathrm{arcseg}^{-2}$ 


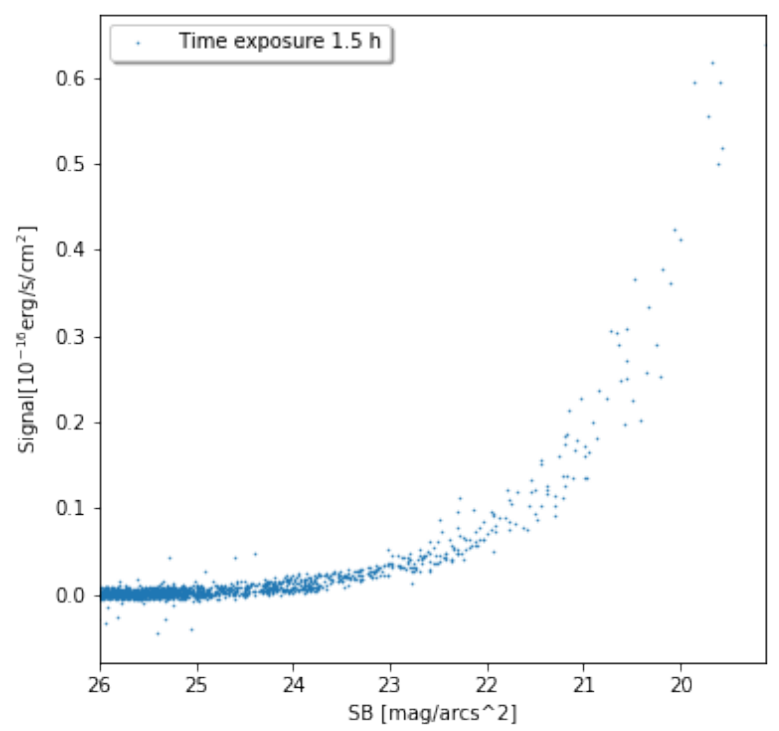

Figura 2.6: Señal frente a brillo de superficial para CAVITY17344. Observamos una tendencia exponencial de la señal frente al brillo superficial. Todas las representaciones de la señal de los cubos frente al brillo superficial serán muy similares ya que la señal solo varía con el brillo superficial, por lo tanto estas gráficas para 1.5 y 3 horas de exposición tendrán la misma apariencia.

Podemos ver los datos de la señal frente al brillo de la superficie, que se distribuyen en una curva exponencial, para la galaxia CAVITY 17344 en la Figura 2.6.

Para ajustar estas curvas representamos el logaritmo de la señal frente al brillo superficial de tal forma que obtendremos una recta para cada cubo. Para finalizar realizaremos la mediana de la pendiente y la ordenada en el origen de cada cubo, consiguiendo una única recta con pendiente $a$ y ordenada en el origen $b$ que ajusta todos los datos. Esta recta sería:

$$
\log (\operatorname{señal})=a S B+b
$$




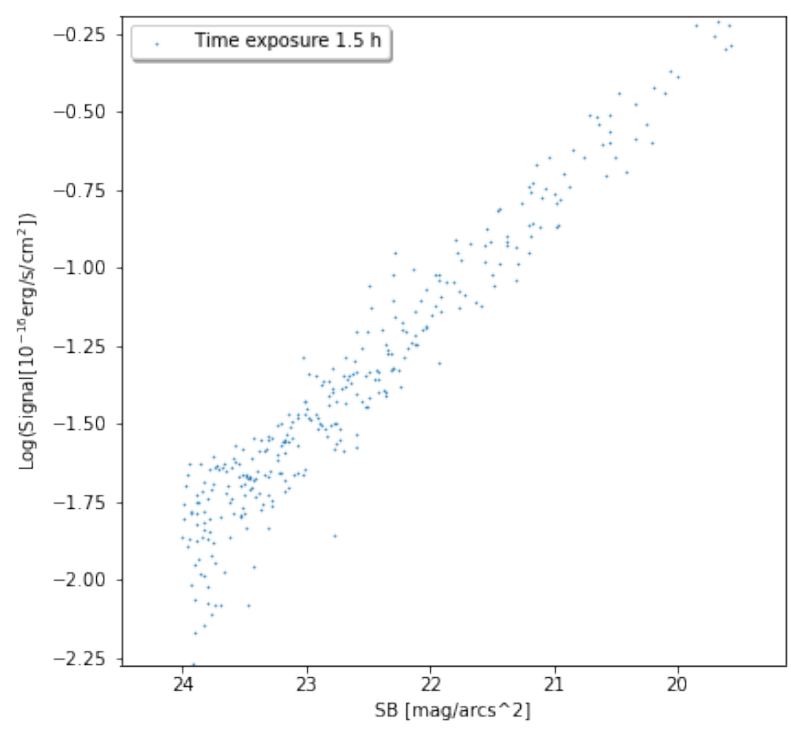

Figura 2.7: Log(señal) frente al brillo superficial de Cavity17344. Podemos ver un tendencia lineal del $\log ($ señal) frente al brillo superficial. Con esta y las 25 representaciones restantes realizaremos la recta que mejor ajusta a todos los datos.

\section{Ajuste de la señal frente al brillo superficial}

En un primer ajuste de los cubos nos dimos cuenta que había algunos que estaban fuera de las estadísticas medias, estos cubos fueron inspeccionados por el equipo de control de calidad de CAVITY llegando a la conclusión de que la reducción no era del todo correcta, por lo que 15 de estos cubos fueron descartados. Otros 14 cubos también fueron descartados porque tenían estrellas brillantes cerca de la región de interés que podían afectar a las estadísticas y por lo tanto fueron eliminados. En total nos quedamos con 26 cubos de los que hicimos el ajuste.

En la Figura 2.7 podemos ver un ajuste de la señal frente al brillo superficial de la galaxia CAVITY17344.

La señal es independiente del tiempo de exposición por lo que solo varía con el brillo superficial de tal forma que en todos los cubos tendremos un ajuste similar. 
La recta que ajusta la pendiente de la señal frente al brillo de la superficie es:

$$
\log (\text { Señal })=(-0.36 \pm 0.01) \mathrm{SB}+(6.93 \pm 0.18)
$$

o la curva:

$$
\text { Señal }=10^{(6.93 \pm 0.18)+(-0.36 \pm 0.01)} \mathrm{SB}
$$

\section{Ruido frente a tiempo de exposición.}

De la misma forma que hemos ajustado la señal con el brillo superficial, necesitamos ajustar el ruido con el tiempo de exposición de cada cubo. Por tanto, vamos realizar un ajuste de los 26 cubos para obtener un ajuste lineal:

$$
\log (\text { ruido })=c t_{\exp }+d
$$

siendo $t_{\text {exp }}$ el tiempo de exposición que tienen los cubos de PMAS/PPak.

El ruido no cambia con el brillo superficial, solo varía con respecto al tiempo de exposición, por lo que si representamos el ruido frente al brillo superficial teniendo en cuenta los diferentes tiempos de exposición tendremos que los cubos realizados de 1.5 horas se situarán por encima de los de 3 horas.

\section{Ajuste del ruido frente al tiempo de exposición}

Una vez visto que el ruido de los cubos solo varía con el tiempo de exposición de cada uno de ellos, vamos a realizar un ajuste lineal.

Podemos realizar un ajuste lineal cogiendo la mediana del logaritmo del ruido de todos los cubos de 1 hora y 30 minutos y de 3 horas obteniendo la Figura 2.9. Hemos representado en un diagrama de violín la distribución de valores de ruido frente al tiempo de exposición para poder ver mejor la distribución de los datos, lo podemos ver en la Figura 2.10.

La recta que ajusta el logaritmo del ruido frente al tiempo de exposición es:

$$
\log (\text { ruido })=(-0.13 \pm 0.01) t_{\exp }+(-2.35 \pm 0.03)
$$


34 ESTUDIO DE GALAXIAS EN VACÍOS MEDIANTE ANÁLISIS DE DATOS IFU

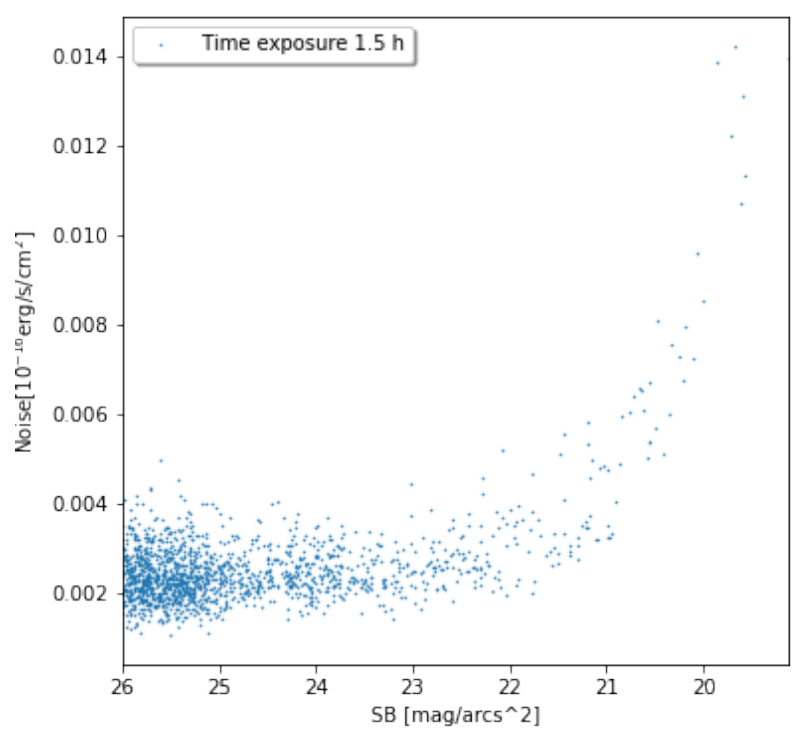

Figura 2.8: Ruido frente a brillo superficial de la galaxia Cavity17344. Se observa que el ruido es constante en función del brillo superficial hasta $22 \mathrm{mag} / \mathrm{arcsec}^{-2}$. A partir de este valor comienza a crecer pero si nos fijamos son pocos de estos datos los que entran en la estadística. 


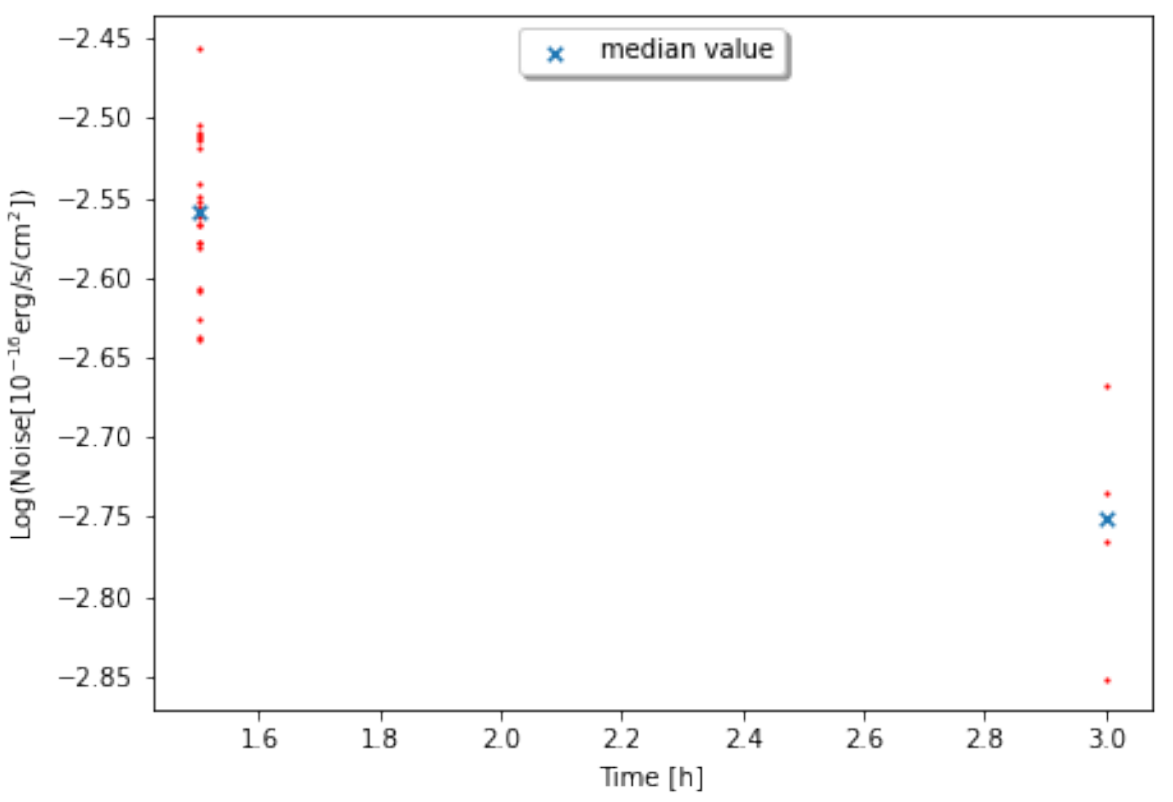

Figura 2.9: Log(ruido) frente al tiempo de exposición. Los puntos rojos se componen de la mediana de cada mapa de ruido realizado para cada cubo. Podemos comprobar que el valor de la mediana del $\log$ (ruido) es menor para 1.5 que para 3 horas de exposición, ya que a medida que aumentamos el tiempo de exposición reducimos el ruido.

O

$$
\text { ruido }=10^{(-0.13 \pm 0.01)} t_{\exp }+(-2.35 \pm 0.03)
$$




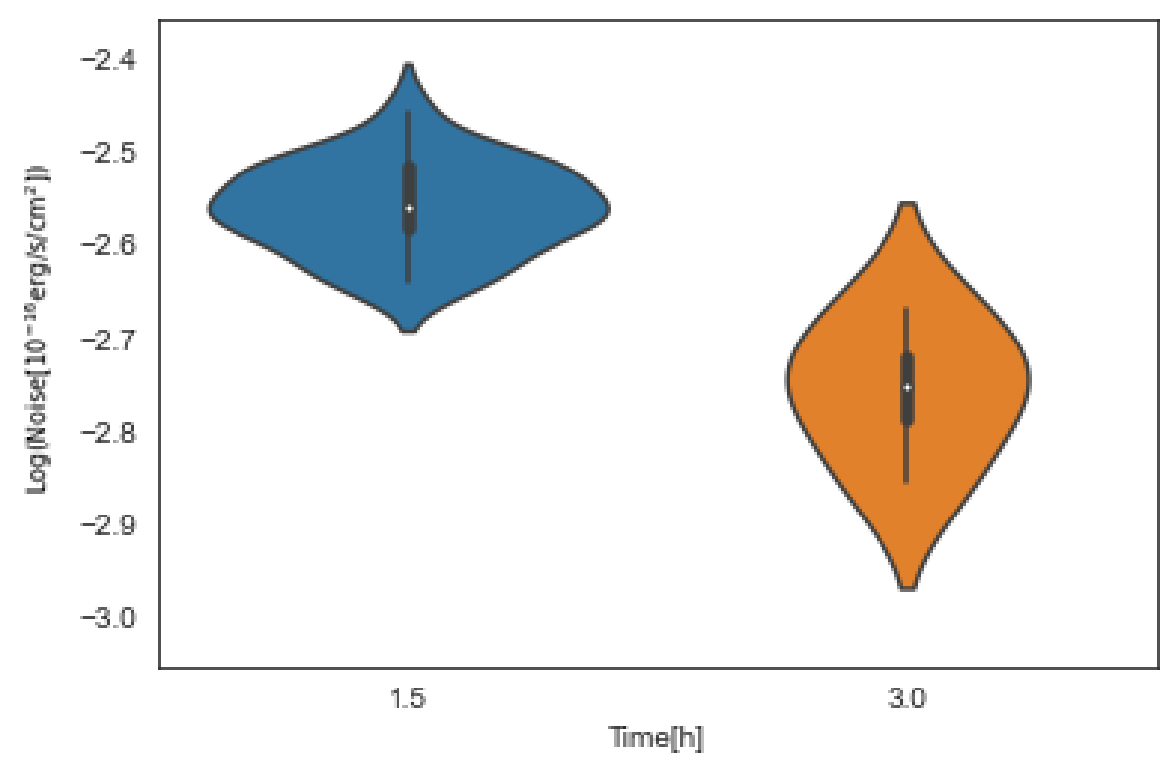

Figura 2.10: Diagrama de violín de Log(ruido) frente al tiempo de exposición. Visualización de la distribución de los datos y su densidad de probabilidad. La barra negra gruesa en el centro representa el intervalo intercuartil, la barra negra fina representa el $95 \%$ de los intervalos de confianza, y el punto blanco es la mediana. 
3 Comparación de la SN de los cubos con las simulaciones 


\subsection{Introducción}

El método de bineado de Voronoi (VorBin) agrupa datos bidimensionales manteniendo de manera óptima la resolución espacial máxima de los datos dada ciertas restricciones. En nuestro caso tiene como entrada las posiciones 2-D de los cubos de PMAS/PPak y la señal y el ruido de un conjunto de píxeles distribuidos en el plano, de tal forma que VorBin formara grupos de píxeles adyacentes, bines, sumando su SN hasta llagar a un mínimo marcado. Cuanto mayor sea la SN de los píxeles, menor será el número de píxeles en el bineado y mayor será el número de bines total.

Hemos aplicado este método tanto a los cubos obtenidos por el instrumento utilizado por CAVITY, PMAS/PPak, como a imágenes en la banda g del catálogo SDSS de los mismos objetos que tenemos en los cubos.

Con esto hemos logrado hacer una comparativa del número de bines que obtenemos para los cubos de PMAS/PPak como con las imágenes SDSS y así poder comprobar si hemos realizado el calculador de tiempo de exposición de forma correcta.

\subsection{Bineado de Voronoi en las imágenes SDSS}

Aplicamos el método bineado de Voronoi a las imágenes SDSS a través de un programa creado por Jesús Domínguez en su trabajo de Fin de Máster de FISYMAT (2017, título: Preparing For The First Light Of WEAVE-Apertif), Apéndice (A), en el que introduciremos algunos cambios.

Los parámetros que hemos variado para realizar este análisis han sido: la señal y el ruido que obtenemos mediante las ecuaciones 2.9 y 2.12 , el límite de SN que queremos alcanzar al hacer el bineado de Voronoi y la banda que estemos usando, en nuestro caso la banda $g$.

El resultado que obtenemos es una imagen para cada galaxia en la banda que hemos indicado, un mapa de bineado, un perfil del brillo superficial y una tabla de datos donde tenemos: los semi-ejes de la elipse que ajustan la galaxia, el ángulo de orientación de la elipse, la elipticidad, la inclinación de la elipse, el radio máximo de la elipse en arcseg y el número de bines. 


\subsection{Bineado de Voronoi en los cubos de PMAS/PPak}

A partir de los datos que hemos obtenido simulando el bineado de Voronoi con las imágenes del catálogo SDSS, vamos a tomar los semiejes de la elipse, el ángulo de orientación de la elipse, la elipticidad, la inclinación y el radio máximo que alcanza la elipse a la isofota 24 para crear una máscara en nuestros cubos. Con esto logramos que al hacer el bineado de Voronoi a los cubos de PMAS/PPak obtengamos la misma zona de la galaxia en ambos casos.

$\mathrm{Al}$ hacer esta máscara vamos a incluir 3 restricciones:

1. Nivel de SN. Nos quedaremos con los píxeles que tienen una SN mayor que 3, de tal forma que cuando vayamos a medir las partes externas de la galaxia, donde la señal es menor que 3 iremos agrupando estos píxeles entre se hasta conseguir una señal mínima elegida.

2. El radio máximo al que llega la elipse que ajusta la galaxia. Elegiremos los píxeles que se encuentran dentro de la isofota límite 24. La ecuación 3.1 representa una familia de elipses con semiejes mayor y menor proporcionales a A y B respectivamente, con la misma inclinación $(\theta)$ y centradas en $(x, y)=(0,0)$, el centro de la galaxia. $\mathrm{R}$ representa el factor de dicha proporcionalidad y es constante para todos puntos $(\mathrm{x}, \mathrm{y})$ pertenecientes a una misma elipse de dicha familia. Esto nos permite seleccionar los spaxels del cubo que se encuentran dentro de una elipse definida aplicando al condición de que $\mathrm{R}$ sea menor que un cierto valor, en nuestro caso el de la isofota 24.

$$
\mathrm{R}(\mathrm{x}, \mathrm{y})=\sqrt{\frac{(\mathrm{x} \cos (\theta)+\mathrm{y} \sin (\theta))^{2}}{\mathrm{~A}^{2}}+\frac{(\mathrm{y} \cos (\theta)-\mathrm{x} \sin (\theta))^{2}}{\mathrm{~B}^{2}}}
$$

donde x e y representan las coordenadas de la galaxia.

3. Una vez aplicada las dos condiciones anteriores es posible que queden varias agrupaciones de píxeles con alta señal ruido pero inconexas entre sí. Entonces eliminamos de la máscara aquellas agrupaciones de píxeles inconexas a la agrupación de píxeles más centrada con la galaxia. Interpretamos que éstas agrupaciones de píxeles pueden ser estrellas u otras galaxias distintas a la galaxia de estudio.

Podemos ver la máscara final en la Figura 3.1. La parte blanca es donde se aplicará el bineado Voronoi. 
40 ESTUDIO DE GALAXIAS EN VACíOS MEDIANTE ANÁLISIS DE DATOS IFU

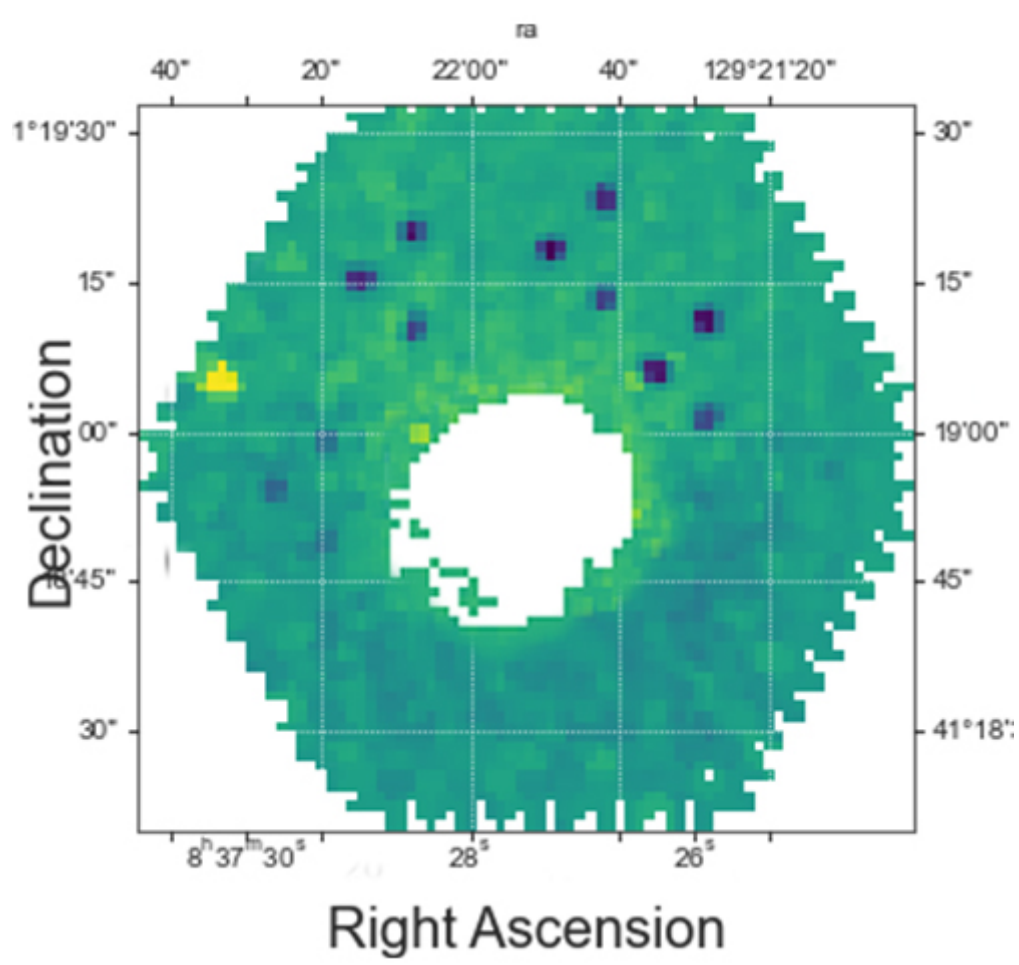

Figura 3.1: Máscara creada en el cubro para la galaxia CAVITY17344. La máscara seleccionada se muestra en blanco, eligiendo casi todos los píxeles donde se encuentra la galaxia, dejando fuera partes externas que no han llegado a las condiciones requeridas. 

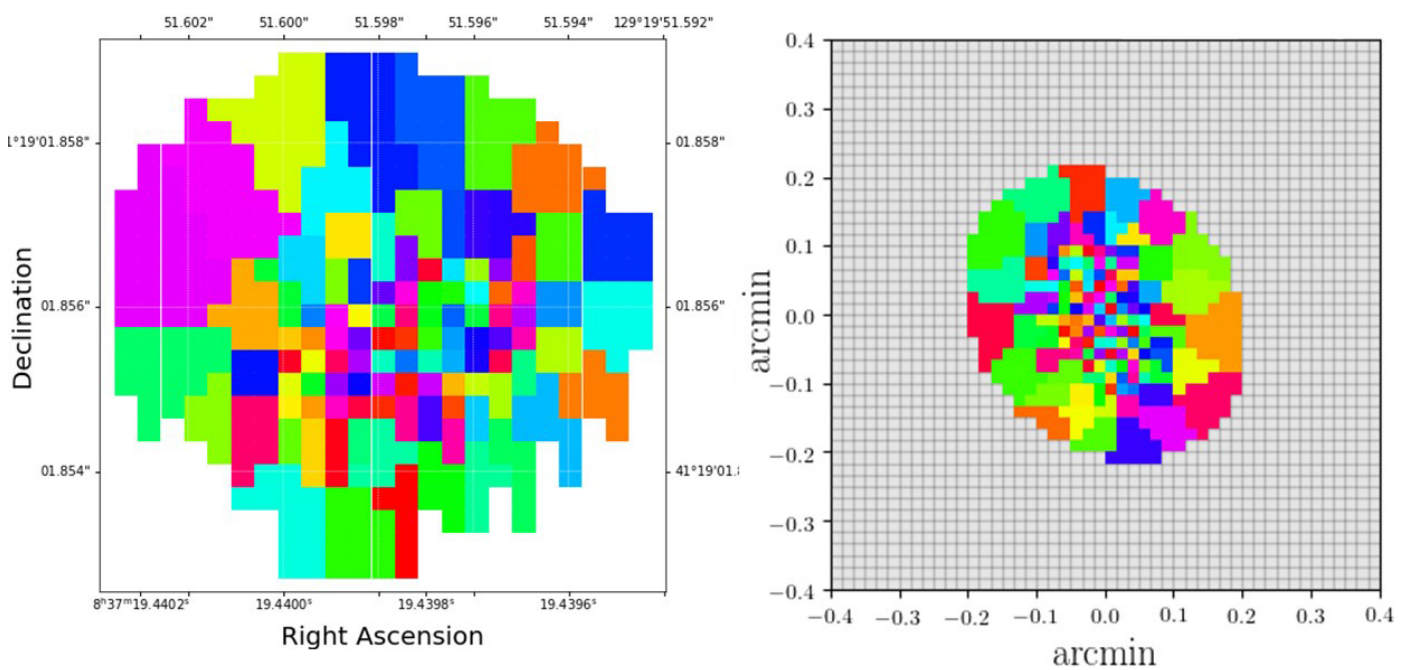

Figura 3.2: Voronoi para la galaxia CAVITY17344 en cubos de PMAS/PPak. En estas dos imágenes podemos observar que el numero de bines, uniones de píxeles representados por colores aleatorios, son semejantes, siendo mas pequeños en el centro donde tenemos una SN mas alta y mas grandes en el exterior donde tenemos que unir mas píxeles para conseguir una SN mínima. Podemos apreciar su forma e inclinación también coinciden.

Representamos el bineado, tanto de PMAS/PPak como de SDSS en la Figura 3.2 $\mathrm{y}$ en ambos casos se puede apreciar visualmente un número de bines similar. Para un mejor estudio haremos una comparación con los datos que hemos obtenido de los cubos y del simulador.

\subsection{Comparación entre el bineado de Voronoi en los cubos de PMAS/PPak y en las imágenes de SDSS}

Una vez realizado el bineado de Voronoi en los cubos que hemos obtenido con PMAS/PPak y en las imágenes SDSS, vamos a representar en una gráfica el número de bines de cada proceso y hacer un ajuste lineal.

Podemos ver este ajuste en la Figura de la imagen 3.3 en la que vemos una ten- 
dencia lineal y una correspondencia 1 a 1 muy cercana.

La recta de ajuste que hemos obtenido es la siguiente:

$$
\mathrm{NBS}=(0.97 \pm 0.06) \times \mathrm{NBC}+(14.34 \pm 8.30)
$$

donde NBS es el número de bines en el simulador y NBC es el número de bines en el cubo.

\subsection{Predicción del número de bines en otras galaxias no observadas con PMAS/PPak}

Como podemos poner cualquier galaxia en nuestro simulador para hacer un bineado de Voronoi, hemos realizado la simulación para 4866 galaxias que están localizadas en ciertos vacíos seleccionados por el equipo de de selección de muestra de CAVITY.

Hemos obtenido el número de bines de todas estas galaxias para poder ver qué galaxias son las más óptimas para observar con PMAS/PPak y tener un buen número de bines para poder hacer un estudio más profundo de la galaxia, llegando a la conclusión que 3510 galaxias tienen un número de bines superior a 23 y 1761 galaxias tienen un número de bines superior a 63 para 1.5 horas de exposición y 816 con 3 horas de exposición.

\subsection{Análisis del número de bines en función del redshift, color, R50, R90 y distancia al centro del vacío}

Dado que tenemos los parámetros de corrimiento al rojo, magnitud de color, R50, R90 ${ }^{1}$ y distancia al centro del vacío de las 4866 galaxias seleccionadas en vacíos gracias al catálogo SDSS, vamos a realizar una caracterización del número de bines que obtenemos en estas galaxias y lo vamos a comparar con estos parámetros.

\footnotetext{
${ }^{1}$ SDSS utiliza los parámetros R90 y R50 para designar en que radio se encuentra el 90 y 50 por ciento de la luz total de la galaxia.
} 


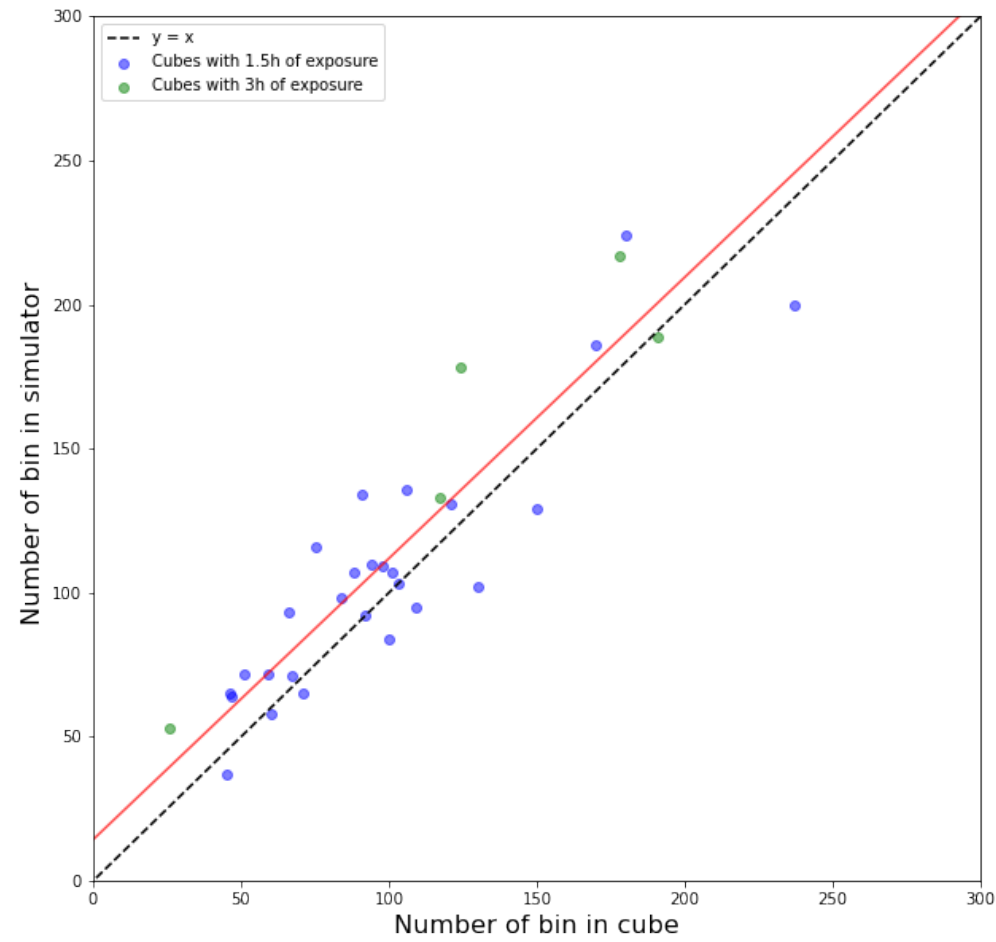

Figura 3.3: Número de bines en el simulador frente el número de bines en cubos. Podemos observar una clara correspondencia entre el número de bines obtenido por el simulador con el número de bines obtenido directamente en los cubos de PMAS/PPak. Podemos ver como la linea roja que es la que ajusta los puntos es casi paralela a la linea negra discontinua que representa la recta unidad. 


\subsubsection{Número de bines para cubos de 3 horas en función de 1.5 horas.}

La toma de datos con una exposición de 3 horas nos va a permitir tener una mayor $\mathrm{SN}$ frente a los datos de 1.5 horas. Esto es debido a que a mayor tiempo de exposición menor ruido y, por tanto, mayor SN. Por lo que en el bineado de Voronoi para 3 horas vamos a conseguir que las partes más externas de la galaxia tengan una SN mayor consiguiendo un mayor número de bines. Esto se puede ver en la Figura 3.4, donde el ajuste lineal de el número de bines para 3 horas frente a 1.5 horas es:

$$
\mathrm{NBS}_{3 \mathrm{~h}}=(1.55 \pm 0.01) \times \mathrm{NBS}_{1.5 \mathrm{~h}}+(3.07 \pm 1.64)
$$

donde $\mathrm{NB}_{3 \mathrm{~h}} \mathrm{y} \mathrm{NB}_{1.5 \mathrm{~h}}$ es el número de bines, que hemos obtenido en el simulador, para 3 y 1.5 horas respectivamente.

En la Figura 3.4 podemos ver que al duplicar el tiempo de exposición el número de bines es mayor, siendo la pendiente de 1.55 muy cercana a $\sqrt{2}=1.44$ que es el factor teórico que se incrementa la $\mathrm{SN}$ al duplicar el tiempo de exposición.

\subsubsection{Número de bines frente al redshift.}

En la Figura 3.5 no vemos una correlación definida entre el número de bines en función del redshift. Sí vemos que la nube de puntos de 3 horas está desplazada hacia arriba con respecto a la nube de puntos de 1.5 horas debido a lo comentado en la Subsección 3.6.1

\subsubsection{Número de bines frente a la magnitud del spaxel central.}

Vemos en la Figura 3.6 que el número de bines aumenta con el brillo superficial del spaxel central, sin embargo, la dispersión crece a medida que aumenta el brillo superficial. Esto se puede deber a la fuerte correlación que el número de bines también presenta con otros parámetros como el tamaño, R50 y R90. 


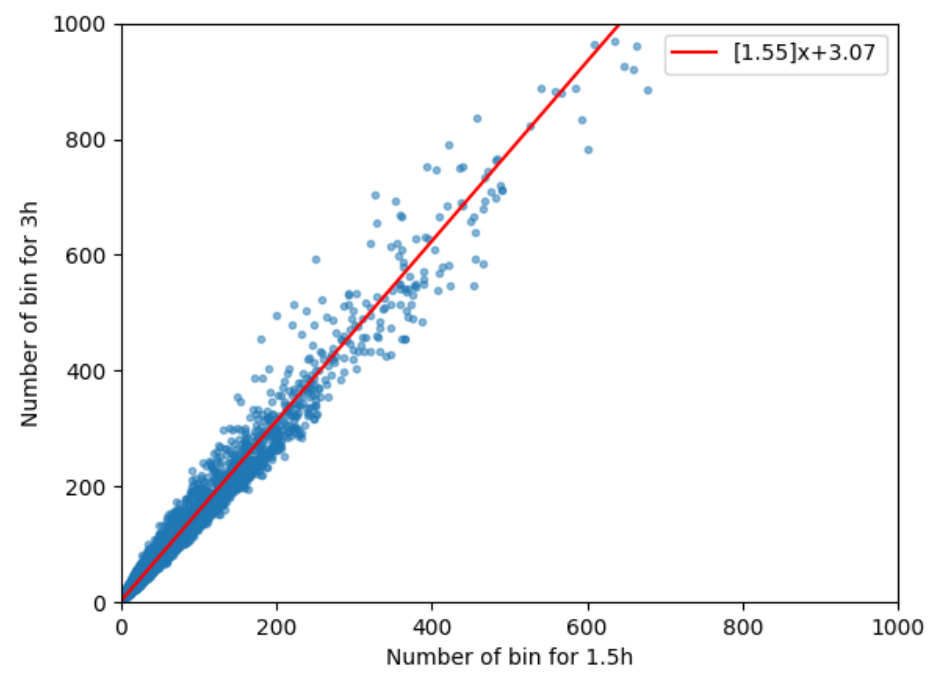

Figura 3.4: Número de bines para cubos de 3 horas en función de 1.5 horas. Vemos una clara correspondencia entre el número de bines de las galaxias con 1.5 y 3 horas de exposición. Esto se ve reflejado en la linea que ajusta los datos, la cual tiene una pendiente de 1.55 que esta cerca del valor que escala el ruido cuando duplicamos el tiempo de exposición, es decir $\sqrt{2}=1.44$ 


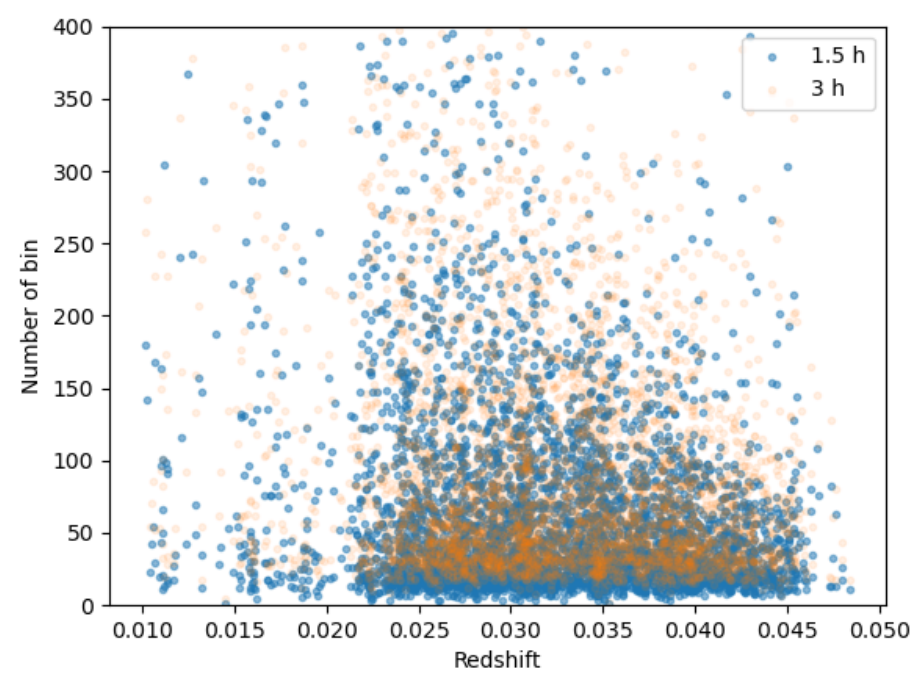

Figura 3.5: Número de bines frente al redshift. Podemos ver como el número de bines para 3 horas es mayor que para 1.5 horas pero no encontramos una correlación del número de bines con el redshift.

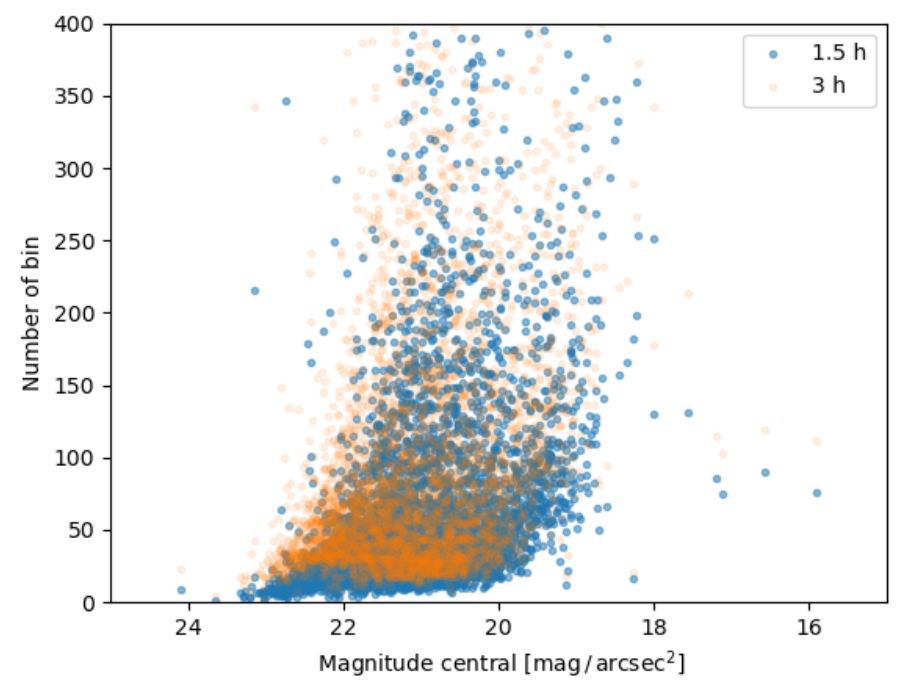

Figura 3.6: Número de bines frente a la magnitud del spaxel central. Podemos apreciar que el número de bines aumenta pero no encontramos una relación con la magnitud del spaxel central. 


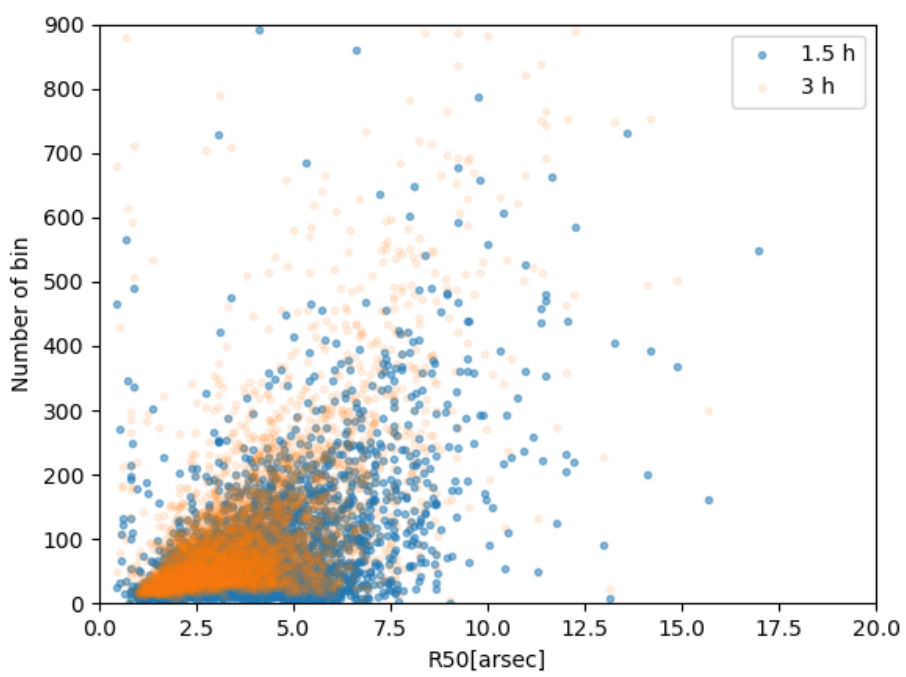

Figura 3.7: Número de bines frente al parámetro R50. Podemos apreciar que el número de bines aumenta con el tamaño aparente de la galaxia pero nos encontramos mucha dispersión a medida que aumenta el brillo superficial.

\subsubsection{Número de bines frente R50 y R 90}

Podemos apreciar en las Figuras 3.7 y 3.8 que el número de bines aumenta con el tamaño aparente de la galaxia, sin embargo, la dispersión crece a medida que aumenta el brillo superficial. Esto se puede deber a la fuerte correlación que el número de bines también presenta con otros parámetros como el brillo superficial. Pon las unidades de medida en los ejes de las gráficas.

\subsubsection{Número de bines frente a la fracción del radio efectivo.}

En la Figura 3.9 comprobamos que la distribución de las galaxias con 3 horas de exposición están por encima de las que tienen 1.5 horas de exposición, como habíamos previsto anteriormente. También podemos observar en la Figura 3.9 una distribución de los bines en torno una fracción del radio efectivo de 0.8. La fracción del radio efectivo se define como la esfera centrada en el vacío normalizada a la unidad. En ocasiones encontramos vacíos que no tienen una distribución esférica perfecta, por lo que hay zonas de la esfera que define al vació que no entran dentro de dicho vació. Esto lo podemos ver en el eje de abscisas de la Figura 3.9 donde tenemos valores superiores 


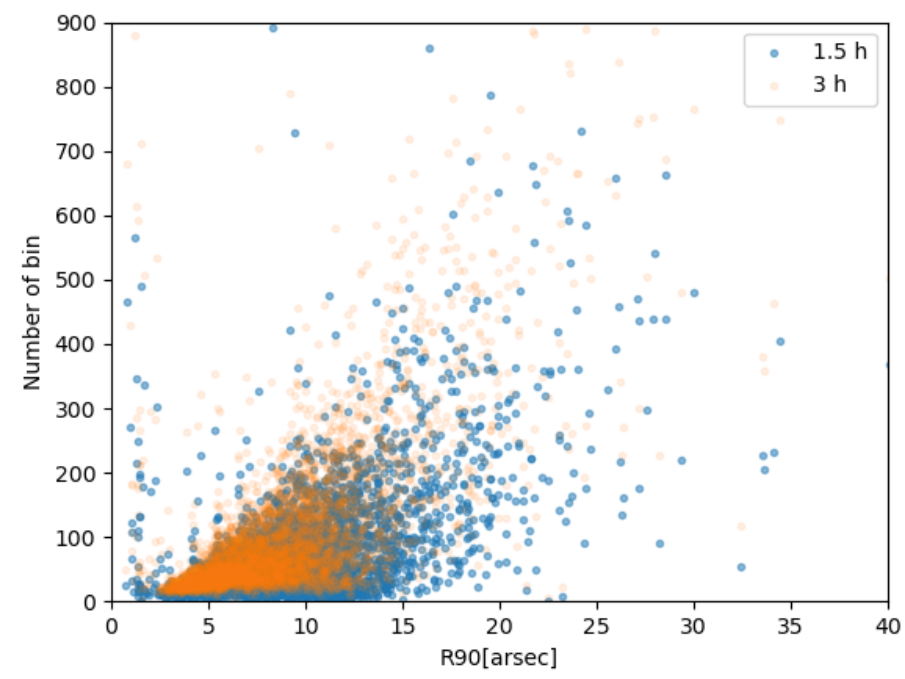

Figura 3.8: Número de bines frente al parámetro R90. Misma tendencia que en la Figura 3.7 pero para estructuras mas grandes.

a 1, es decir, el límite del vació. La distribución tiene un máximo en el número de bines en torno a una distancia relativa a 0.8 del centro del vacío. Esto es debido a que hay menos galaxias cerca del centro debido a que la densidad de galaxias es uniforme dentro del vacío pero el volumen radial es menor en la parte central. Parece que la dispersión de puntos y el número medio de bines es mejor en el centro, pero eso puede ser simplemente por que hay menos galaxias.

\subsubsection{Diagrama de color-magnitud de la galaxia.}

Como vimos en la el Capítulo 1, el diagrama de color-magnitud nos informa sobre el tipo de galaxia que estamos observando según este situado en la secuencia roja , el valle verde o la nube azul. Por lo tanto como podemos ver en la Figura 3.10 hemos representado este diagrama para las 1761 galaxias que superan los 63 bines para los tiempos de exposición de 1.5 horas y 816 galaxias que para un tiempo de exposición de 1.5 horas no llegan a 63 bines, pero para 3 horas lo igualan o sobrepasan. Observamos también que las galaxias seleccionadas para 1.5 horas son en media más brillantes (situadas en media más a la derecha del diagrama) que las seleccionadas para 3 horas (situadas en media más a en la parte central del diagrama). 


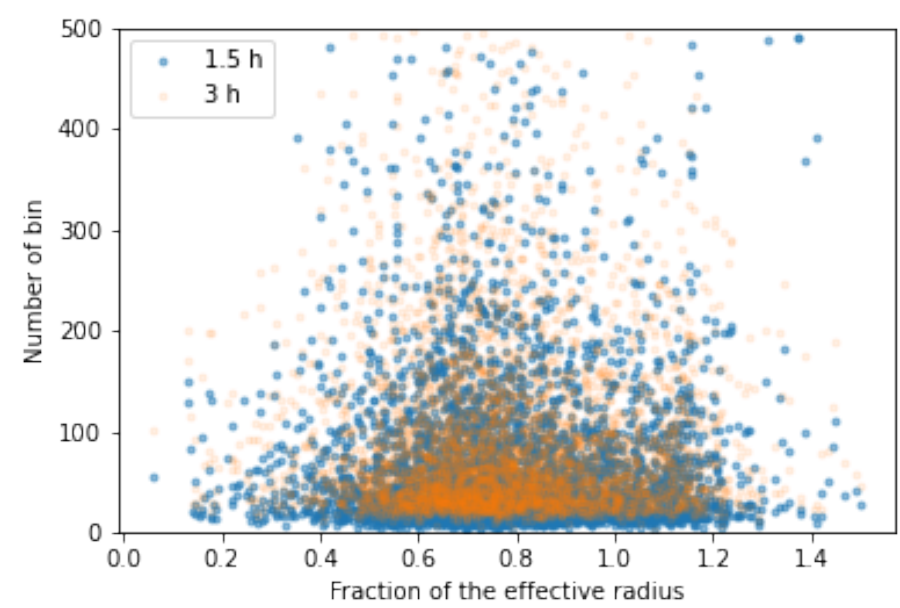

Figura 3.9: Número de bines frente al parámetro R90. Podemos observar que hay menos galaxias cerca del centro del vacío debido a que hay menos galaxias cerca del centro ya que la densidad de galaxias es uniforme dentro del vacío pero el volumen radial es menor en la parte central. También podemos ver que la fracción del radio efectivo sobrepasa el valor de 1, esto es porque el vacío no es una esfera perfecta. 

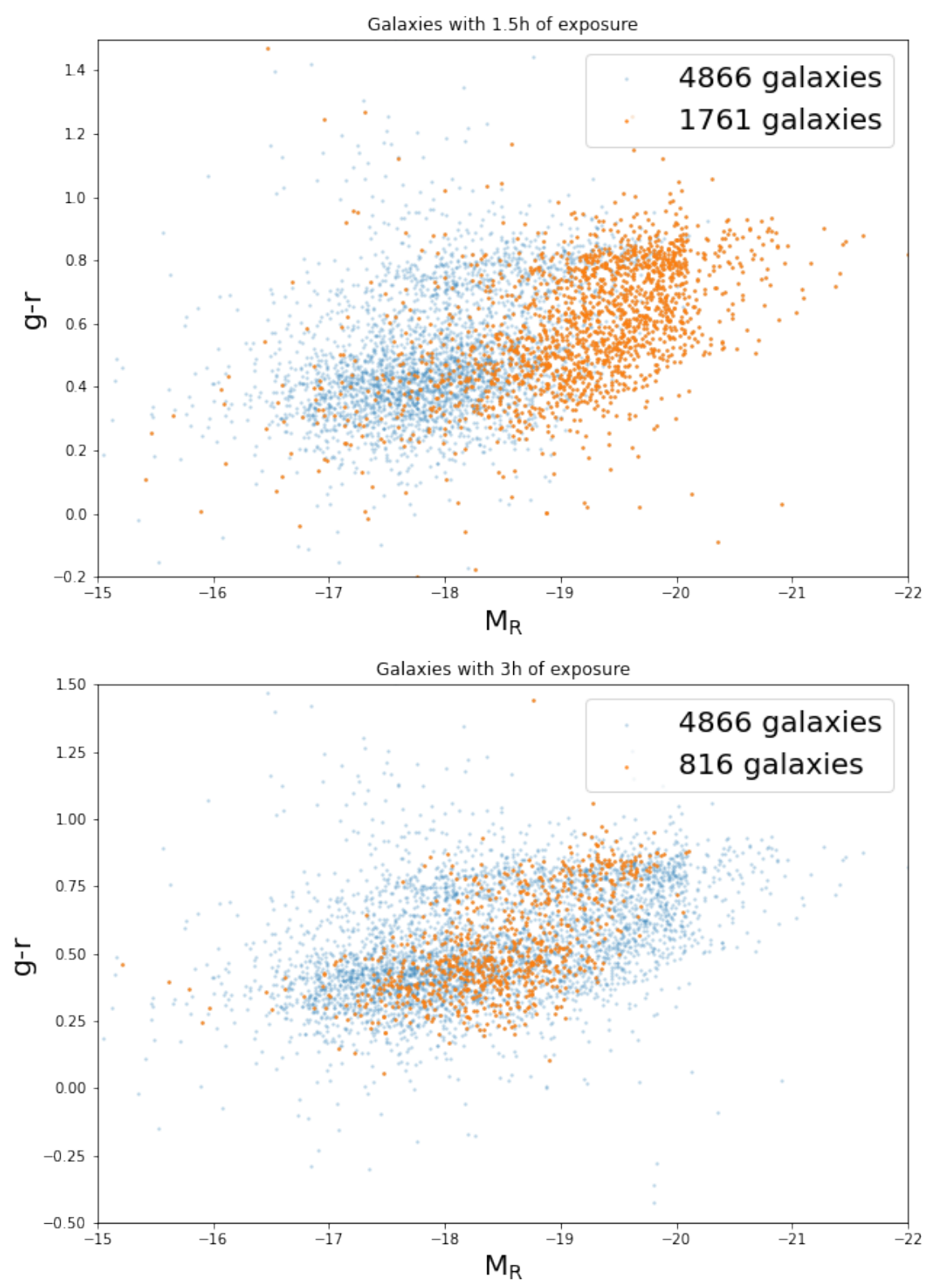

Figura 3.10: Distribución de la magnitud absoluta en la banda r frente al índice de color g-r. En la imagen superior podemos ver como la distribución de las galaxias, que tienen un número de bines superior a 63 para 1.5 horas de exposición, esta diferenciada en las tres regiones del diagrama de color magnitud para galaxias, a saber, secuencia roja , el valle verde o la nube azul. En la imagen inferior nos encontramos una distribución simular de las galaxias que para un tiempo de exposición de 1.5 horas no llegan a 63 bines, pero para 3 horas lo igualan o sobrepasan. 


\section{4 | Resumen y conclusión}

Vamos a comentar los datos obtenidos de los cubos de PMAS/PPak tanto en el capítulo 2 donde realizamos mapas de señal y ruido como en el capítulo 3 donde realizamos un bineado de Voronoi de dichos mapas.

\subsection{Calculador del tiempo de exposición}

El análisis que hemos realizado a través de los mapas de señal y ruido se ha ido comprobando a través de la estadística de todos los flujos obtenidos a través del spaxel. Llegando a la conclusión que en un primer momento estábamos midiendo el ruido de

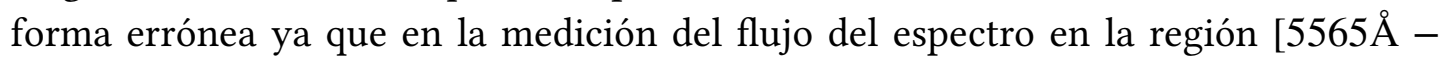
$5650 \AA ̊$ ] entraba una línea de cielo que tuvimos que eliminar. Mediante la función sigma-clipping ${ }^{1}$, con un sigma de 3 , pudimos obtener los mejores resultados para el calculador de tiempo de exposición.

Los mapas de señal y ruido tienen cierta dispersión, por ejemplo la Figura 2.8 podemos ver una cola que se eleva desde un brillo superficial de $22 \mathrm{mag} / \mathrm{arsec}^{2}$, sin embargo esta cola no debería existir debido a que el ruido no cambia con el brillo superficial. Esto ha podido deberse al viñeteado que sufre el instrumento. Esto nos lleva a pensar que estamos interpretando parte de la señal como ruido.

Por lo tanto en el calculador de tiempo de exposición tenemos dos partes, la señal y el ruido. La señal hemos considerado que está bien calculada a pesar de los pocos cubos que tenemos para realizar la estadística, sin embargo el ruido que hemos ajustado al tiempo de exposición puede cambiar levemente. Este cambio lo hemos comprobando

\footnotetext{
${ }^{1}$ Sigma es el número de desviación estándar que se utilizarán para un recorte de los datos, tanto inferior como superiormente. Mediante la función sigma-clipping nos ayuda a quitar datos que están muy dispersos de nuestra media de datos.
} 
para diferentes sigma en la función sigma-clipping dando como mejor resultado un $\sigma=3$.

\subsection{Bineado de Voronoi}

Gracias al simulador de Jesús Domínguez (Apéndice A) hemos podido comprobar si el bineado de Voronoi que hemos realizado en los cubos era correcto. Esto ha sido posible a través del número de bines que hemos obtenido al realizar el bineado de Voronoi tanto en los cubos de PMAS/PPak como en las imágenes del SDSS cogidas en el simulador.

Para ello hemos representado el número de bines obtenido en el simulador con el número de bines obtenido en los cubos de PMAS/PPak dando como resultado un ajuste en el que la pendiente se acerca a 1 y con una ordenada en el origen de 14.68. En el caso perfecto esta pendiente seria 1 y la ordenada en el origen sería 0 , entonces el simulador coincidiría exactamente con los cubos de PMAS/PPak. Aparte de esta diferencia tenemos un error en la pendiente y en la ordenada en el origen de de \pm 0.06 $\mathrm{y} \pm 8.30$ respectivamente, lo que hace que tengamos una dispersión a la hora de hacer predicciones en el número de bines mediante el simulador.

En esta predicción, al tener una dispersión, podemos obtener galaxias que pensamos que tengan un número de bines determinado pero luego sea menor. Sin embargo esta diferencia no será muy alta ya que el error de la pendiente es del $6 \%$. El error en la ordenada en el origen es más alto pero entra dentro de un valor razonable en comparación al número de bines que estamos teniendo en cuenta, es decir, tenemos una dispersión de ${ }_{+6.04}^{+22.64}$, lo que nos predice que el número de bines en el simulador como máximo será 23 veces el del cubo de PMAS/PPak. Por lo tanto tenemos un buen ajuste del número de bines que vamos a obtener en el simulador para galaxias que aun no han sido observadas con PMAS/PPak.

No obstante necesitamos seleccionar galaxias en el simulador que dispongan de un número de bines superior a 23 para que así al menos podamos asegurarnos que se realice el bineado de Voronoi en los cubos de PMAS/PPak en los casos mas extremos. Por lo tanto si damos un margen de 40 bines y elegimos galaxias de 1.5 horas de exposición que tengan un bineado superior a 63 bines obtenemos 1761 galaxias que cumplen esta condición. Ahora bien, de estas 1761 galaxias habrá algunas que con una exposición de 3 horas superen estos 63 bines. El número de galaxias que dando una 
exposición de 3 horas pasan a tener un número de bines superior a 3 horas es de 816 galaxia. Por lo que tendremos un total de 2577 galaxias observables dependiendo de los tiempos de exposición.

Para finalizar en la Figura 3.10 podemos apreciar las tres regiones características a la hora de estudiar diagramas de color-magnitud de galaxias, a saber, secuencia roja ,el valle verde y la nube azul. Esto nos indica que las galaxias que se encuentran distribuidas en la parte inferior de la distribución son de tipo espiral y por lo tanto tienen una formación estelar activa. Por el contrario la distribución de la parte superior son galaxias elípticas, es decir viejas. Gracias a esta clasificación podremos discernir que tipo de galaxias, según en número de bines, queremos observar en el telescopio de 3.5m de Calar Alto a través del instrumento PMAS/PPak. 



\section{Bibliografía}

Michael S. Hoyle Fiona Yun-Young Changbom Pan et al., Danny C. Cosmic voids in Sloan Digital Sky Survey Data Release 7. , 421(2):926-934, April 2012. doi: 10.1111/j.1365-2966.2011.20197.x.

R. García-Benito, S. Zibetti, S. F. Sánchez, B. Husemann, A. L. de Amorim, A. CastilloMorales, R. Cid Fernandes, S. C. Ellis, J. Falcón-Barroso, L. Galbany, A. Gil de Paz, R. M. González Delgado, E. A. D. Lacerda, R. López-Fernandez, A. de LorenzoCáceres, M. Lyubenova, R. A. Marino, D. Mast, M. A. Mendoza, E. Pérez, N. Vale Asari, J. A. L. Aguerri, Y. Ascasibar, S. Bekeraite, J. Bland-Hawthorn, J. K. Barrera-Ballesteros, D. J. Bomans, M. Cano-Díaz, C. Catalán-Torrecilla, C. Cortijo, G. Delgado-Inglada, M. Demleitner, R. J. Dettmar, A. I. Díaz, E. Florido, A. Gallazzi, B. García-Lorenzo, J. M. Gomes, L. Holmes, J. Iglesias-Páramo, K. Jahnke, V. Kalinova, C. Kehrig, R. C. Kennicutt, Á. R. López-Sánchez, I. Márquez, J. Masegosa, S. E. Meidt, J. Mendez-Abreu, M. Mollá, A. Monreal-Ibero, C. Morisset, A. del Olmo, P. Papaderos, I. Pérez, A. Quirrenbach, F. F. Rosales-Ortega, M. M. Roth, T. RuizLara, P. Sánchez-Blázquez, L. Sánchez-Menguiano, R. Singh, K. Spekkens, V. Stanishev, J. P. Torres-Papaqui, G. van de Ven, J. M. Vilchez, C. J. Walcher, V. Wild, L. Wisotzki, B. Ziegler, J. Alves, D. Barrado, J. M. Quintana, and J. Aceituno. CALIFA, the Calar Alto Legacy Integral Field Area survey. III. Second public data release. , 576:A135, April 2015. doi: 10.1051/0004-6361/201425080.

Donald G. York, J. Adelman, Jr. Anderson, John E., Scott F. Anderson, James Annis, Neta A. Bahcall, J. A. Bakken, Robert Barkhouser, Steven Bastian, Eileen Berman, William N. Boroski, Steve Bracker, Charlie Briegel, John W. Briggs, J. Brinkmann, Robert Brunner, Scott Burles, Larry Carey, Michael A. Carr, Francisco J. Castander, Bing Chen, Patrick L. Colestock, A. J. Connolly, J. H. Crocker, István Csabai, Paul C. Czarapata, John Eric Davis, Mamoru Doi, Tom Dombeck, Daniel Eisenstein, Nancy Ellman, Brian R. Elms, Michael L. Evans, Xiaohui Fan, Glenn R. Federwitz, Larry 
Fiscelli, Scott Friedman, Joshua A. Frieman, Masataka Fukugita, Bruce Gillespie, James E. Gunn, Vijay K. Gurbani, Ernst de Haas, Merle Haldeman, Frederick H. Harris, J. Hayes, Timothy M. Heckman, G. S. Hennessy, Robert B. Hindsley, Scott Holm, Donald J. Holmgren, Chi-hao Huang, Charles Hull, Don Husby, Shin-Ichi Ichikawa, Takashi Ichikawa, Željko Ivezić, Stephen Kent, Rita S. J. Kim, E. Kinney, Mark Klaene, A. N. Kleinman, S. Kleinman, G. R. Knapp, John Korienek, Richard G. Kron, Peter Z. Kunszt, D. Q. Lamb, B. Lee, R. French Leger, Siriluk Limmongkol, Carl Lindenmeyer, Daniel C. Long, Craig Loomis, Jon Loveday, Rich Lucinio, Robert H. Lupton, Bryan MacKinnon, Edward J. Mannery, P. M. Mantsch, Bruce Margon, Peregrine McGehee, Timothy A. McKay, Avery Meiksin, Aronne Merelli, David G. Monet, Jeffrey A. Munn, Vijay K. Narayanan, Thomas Nash, Eric Neilsen, Rich Neswold, Heidi Jo Newberg, R. C. Nichol, Tom Nicinski, Mario Nonino, Norio Okada, Sadanori Okamura, Jeremiah P. Ostriker, Russell Owen, A. George Pauls, John Peoples, R. L. Peterson, Donald Petravick, Jeffrey R. Pier, Adrian Pope, Ruth Pordes, Angela Prosapio, Ron Rechenmacher, Thomas R. Quinn, Gordon T. Richards, Michael W. Richmond, Claudio H. Rivetta, Constance M. Rockosi, Kurt Ruthmansdorfer, Dale Sandford, David J. Schlegel, Donald P. Schneider, Maki Sekiguchi, Gary Sergey, Kazuhiro Shimasaku, Walter A. Siegmund, Stephen Smee, J. Allyn Smith, S. Snedden, R. Stone, Chris Stoughton, Michael A. Strauss, Christopher Stubbs, Mark SubbaRao, Alexander S. Szalay, Istvan Szapudi, Gyula P. Szokoly, Anirudda R. Thakar, Christy Tremonti, Douglas L. Tucker, Alan Uomoto, Dan Vanden Berk, Michael S. Vogeley, Patrick Waddell, Shu-i. Wang, Masaru Watanabe, David H. Weinberg, Brian Yanny, Naoki Yasuda, and SDSS Collaboration. The Sloan Digital Sky Survey: Technical Summary. , 120(3):1579-1587, September 2000. doi: 10.1086/301513.

Cappellari et al. Adaptive spatial binning of integral-field spectroscopic data using voronoi tessellations. Monthly Notices of the Royal Astronomical Society, 342(2): 345-354, 2003.

E. P. Hubble. Extragalactic nebulae. , 64:321-369, December 1926. doi: 10.1086/143018.

Geller et al. Mapping the universe. Science, 246(4932):897-903, 1989.

Gott.III et al. A map of the universe. The Astrophysical fournal, 624(2):463, 2005.

Pomarède et al. Cosmicflows-3: The South Pole Wall. , 897(2):133, July 2020. doi: 10.3847/1538-4357/ab9952.

Michael R. Blanton, Daniel Eisenstein, David W. Hogg, David J. Schlegel, and J. Brinkmann. Relationship between Environment and the Broadband Optical Properties 
of Galaxies in the Sloan Digital Sky Survey. , 629(1):143-157, August 2005. doi: $10.1086 / 422897$.

David R. Law and MaNGA Team. Mapping Nearby Galaxies at APO: The MaNGA IFU Galaxy Survey. In American Astronomical Society Meeting Abstracts \#223, volume 223 of American Astronomical Society Meeting Abstracts, page 254.31, January 2014. 



\section{A $\mid$ Simulador de número de bines en las imágenes SDSS}

El simulador desarrollado por Jesús Domínguez Gómez en su trabajo de Fin de Máster de FISYMAT (2017, título: Preparing For The First Light Of WEAVE-Apertif) es un desarrollo basado en una versión inicial escrita en lenguaje de computación Python por Jesús Falcón-Barroso.

En la Figura A.1 podemos ver un esquema del modelo usado por Jesús en su TFM que ayudará a comprenderlo mejor.

Para empezar, necesitamos una lista de galaxias, en nuestro caso serán las galaxias seleccionadas por el equipo de selección de CAVITY, tenemos que tener en cuenta que para dichas galaxias se dispone de información óptica.

Una vez que tenemos la lista, necesitamos las imágenes ópticas de estas galaxias, por lo tanto procederemos a su descarga mediante los servidores de SDSS. El simulador utilizará estas imágenes para realizar la fotometría y análisis para así obtener la forma, el tamaño y los perfiles de brillo superficial de las galaxias.

Después del análisis de la fotometría, las galaxias que no se ajustan al campo de PMAS/PPak no serán tomadas por la simulación.

En este punto, se modificó el programa para que, en vez de usar el calculador de tiempo de exposición ETC (Exposure Time Calculator) desarrollado por WEAVE (Trager, from the Kapteyn Astronomical Institute), usara el calculador de tiempo de exposición que habíamos desarrollado en la Sección 2.2.4.

Una vez que conocemos la señal y el ruido por spaxel para un tiempo de exposición determinado, aplicamos el bineado de voronoi desarrollado por Cappellari et al. [2003] hasta la SN que elijamos. Entonces el simulador agrupa los spaxels en bines, 


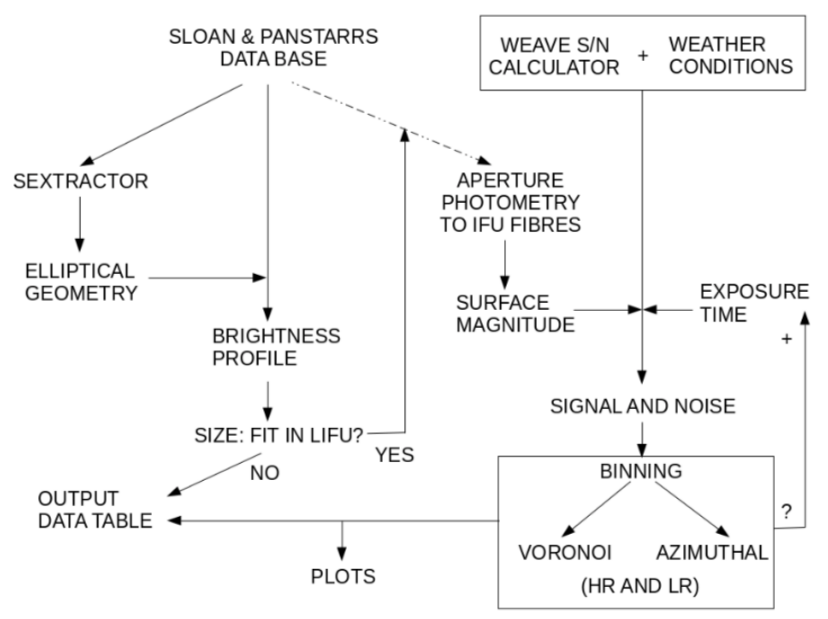

Figura A.1: Descripción general de la simulación inicial del trabajo de Fin de Máster de Jesús Domínguez. Hay dos líneas principales en la simulación. (1) Lado izquierdo del esquema: las imágenes de SDSS y PS1 se utilizan para calcular la geometría elíptica de las galaxias utilizando 'SExtractor'. Con la geometría de la isofota, se calcula el perfil de brillo para comprobar si la isofota está dentro del campo de visión de WEAVE. (2) Lado derecho del esquema: si las isofotas 24 cae dentro del campo de visión, las imágenes SDSS y PS1 se utilizan para aplicar fotometría de apertura a las fibras del LIFU y obtener su magnitud. Las magnitudes y el tiempo de exposición de las fibras son las entradas del ETC. Esta calculadora proporciona valores de señal y ruido por cuenta. Una vez que se estiman la señal y el ruido, se aplican los procesos de agrupamiento. En este punto, si no se alcanza el límite de SN, el tiempo de exposición se incrementa en la entrada ETC y se vuelve a aplicar el binning. Finalmente, se trazan las cifras agrupadas y los resultados se guardan en la tabla de salida. 
aumentando la SN por bin hasta el requerido.

Finalmente, todos los resultados de la simulación como tiempo de exposición, número de bines, tamaño o brillo de la galaxia se guardan en la tabla de salida. 